\title{
Replication of distinct scrapie prion isolates is region specific in brains of transgenic mice and hamsters
}

\author{
Rolf Hecker, ${ }^{1}$ Albert Taraboulos, ${ }^{1}$ Michael Scott, ${ }^{1}$ Keh-Ming Pan, ${ }^{1}$ Shu-Lian Yang, ${ }^{1,2}$ Marilyn \\ Torchia, ${ }^{1}$ Klaus Jendroska, ${ }^{2,4}$ Stephen J. DeArmond, ${ }^{1,2}$ and Stanley B. Prusiner ${ }^{1,3,5}$ \\ Departments of ${ }^{1}$ Neurology, ${ }^{2}$ Pathology, and ${ }^{3}$ Biochemistry and Biophysics, University of California, San Francisco, \\ California 94143 USA
}

Scrapie prions are composed largely, if not entirely, of $\operatorname{PrP}^{\mathrm{Sc}}$ molecules. The prion isolates Sc237 and $139 \mathrm{H}$ exhibit markedly different incubation times in Syrian, Armenian, and Chinese hamsters, as well as in transgenic (Tg) 81 mice expressing Syrian hamster PrP (SHaPrP). Repassage of prions from transgenic mice or Chinese hamsters into Syrian hamsters revealed that the original properties of the prion isolates are retained. When Syrian hamsters were first inoculated with $139 \mathrm{H}$ prions and subsequently challenged with Sc237 prions, the incubation period was determined by the faster Sc237 isolate. Regional mapping studies demonstrated different kinetics and patterns of $\mathrm{PrP}^{\mathrm{Sc}}$ accumulation for Sc237 and $139 \mathrm{H}$ prions in the brains of Syrian hamsters as well as $\mathrm{Tg}(\mathrm{SHaPrP}) 7$ mice. That distinct prion isolates induce different region-specific accumulations of $\mathrm{PrP}^{\mathrm{Sc}}$ in brain suggests a novel mechanism for propagation of isolates whereby they replicate in particular sets of neurons. The prion isolates could be targeted to specific CNS cells by differing conformations of $\operatorname{PrP}^{\mathrm{Sc}}$, post-translational modifications of $\operatorname{PrP}^{\mathrm{Sc}}$ such as Asn-linked glycosylation, or an as yet undetected macromolecule complexed with $\operatorname{PrP}^{S c}$ in the prion.

[Key Words: Prions; strains; PrP gene; transgenetics; histoblot; $\mathrm{PrP}^{\mathrm{Sc}}$ ]

Received February 5, 1992; revised version accepted April 30, 1992.

Studies with transgenic mice expressing foreign and mutant prion protein $(\mathrm{PrP})$ genes have provided a wealth of new knowledge about the structure of the prion particle, the pathogenesis of prion diseases, and the events that feature in the replication of prions /Scott et al. 1989; Hsiao et al. 1990; Prusiner et al. 1990; Westaway et al. 1991). Investigations of transgenic (Syrian hamster PrP) $[\mathrm{Tg}(\mathrm{SHaPrP})]$ mice expressing SHaPrP demonstrated that $\mathrm{PrP}^{\mathrm{Sc}}$ in the inoculum dictates whether mouse prions (Mo prions) or Syrian hamster prions (SHa prions) will be produced. Furthermore, the scrapie incubation times and neuropathology are determined by the particular prion synthesized. Although no physical evidence is available, it seems likely that $\operatorname{PrP}^{\mathrm{C}}$ and $\operatorname{PrP}^{\mathrm{Sc}}$ transiently form a complex during the synthesis of nascent $\mathrm{PrP}^{\mathrm{Sc}}$ molecules (Prusiner et al. 1990; Prusiner 1991).

Early studies of Dickinson and colleagues not only identified inbred strains of mice with short or long incubation times, but also distinct isolates of the scrapie agent distinguishable by their different incubation times and neuropathologic lesions (Dickinson et al. 1968; Fraser and Dickinson 1968, 1973; Dickinson and Meikle

\footnotetext{
${ }^{4}$ Present address: Department of Neurology, Universitätsklinikum-Rudolf-Virchow, 1000 Berlin, Germany.

${ }^{5}$ Corresponding author.
}

1971; Dickinson 1976; Bruce and Dickinson 1987; Bruce et al. 1991). Distinct isolates of the scrapie agent have often been referred to as strains. Although earlier studies were complicated by the use of Prn- $p^{a}$ and Prn- $p^{b}$ mice (Carlson et al. 1986, 1988, 1989; Hunter et al. 1987; Westaway et al. 1987, 1991; Race et al. 1990), the existence of at least a few scrapie isolates in mice seems secure (Bruce and Dickinson 1987; Bruce et al. 1991). Derivation of new isolates in Syrian hamsters after passage from mice has also been reported (Kimberlin and Walker 1978; Kimberlin et al. 1987b, 1989/. The existence of distinct prion isolates poses a conundrum because both the molecular structure and the mechanism responsible for the different biological properties of these isolates seem to be without precedent. Diversity in biology is generally encoded within nucleic acids; yet no chemical, biological, or physical evidence argues for a scrapie-specific polynucleotide (Prusiner 1991).

To investigate the molecular processes that feature in the replication of prions, we first asked whether Mo prions injected together with SHa prions or sequentially into $\mathrm{Tg}(\mathrm{SHaPrP})$ mice might influence the replication of $\mathrm{SHa}$ prions. The replication of $\mathrm{SHa}$ prions was found to be independent of Mo prions producing longer incubation times. Similarly, two distinct isolates of $\mathrm{SHa}$ prions designated $\mathrm{Sc} 237$ and $139 \mathrm{H}$ and causing disease in $\sim 75$ 
Table 1. Scrapie incubation times in $\mathrm{Tg}(\mathrm{SHaPr}) 81$ mice inoculated with mixtures of mouse and Sc237 SHa prions

\begin{tabular}{|c|c|c|c|c|}
\hline \multicolumn{2}{|c|}{ Inocula } & \multirow[b]{2}{*}{ Number } & \multicolumn{2}{|c|}{ Incubation times } \\
\hline \multicolumn{2}{|c|}{ (log $\mathrm{ID}_{50}$ units) } & & $\begin{array}{l}\text { illness } \\
\text { /days }\end{array}$ & $\begin{array}{l}\text { death } \\
\text { E.M.) }\end{array}$ \\
\hline \multicolumn{5}{|c|}{ A. $\mathrm{Tg}(\mathrm{SHaPrP}) 81$ mice } \\
\hline 2 & & 6 & $277 \pm 7$ & $286 \pm 5$ \\
\hline 6 & & 8 & $192 \pm 5$ & $204 \pm 5$ \\
\hline & 2 & 8 & $104 \pm 2$ & $107 \pm 2$ \\
\hline & 4 & 6 & $81 \pm 4$ & $84 \pm 4$ \\
\hline & 7 & 7 & $66 \pm 2$ & $71 \pm 2$ \\
\hline 6 & 2 & 3 & $101 \pm 2$ & $108 \pm 2$ \\
\hline 6 & 4 & 4 & $83 \pm 2$ & $87 \pm 2$ \\
\hline 2 & 7 & 7 & $67 \pm 1$ & $75 \pm 2$ \\
\hline 2 & 4 & 7 & $84 \pm 2$ & $90 \pm 2$ \\
\hline \multicolumn{5}{|c|}{ B. Nontransgenic 81 mice } \\
\hline 6 & & 4 & $131 \pm 1$ & $145 \pm 2$ \\
\hline & 7 & 8 & $>541$ & \\
\hline 6 & 2 & 9 & $131 \pm 2$ & $143 \pm 3$ \\
\hline 6 & 4 & 5 & $145 \pm 1$ & $159 \pm 3$ \\
\hline 2 & 4 & 3 & $147 \pm 6$ & $157 \pm 8$ \\
\hline 2 & 7 & 6 & $166 \pm 6$ & $189 \pm 4$ \\
\hline 6 & 1 & 4 & $135 \pm 3$ & $150 \pm 3$ \\
\hline
\end{tabular}

and $\sim 165$ days, respectively, were inoculated sequentially into Syrian hamsters. The replication of the Sc237 isolate was independent of the $139 \mathrm{H}$ isolates, as judged by scrapie incubation times.

End-point titrations of Syrian hamster brain extracts showed that both the $\mathrm{Sc} 237$ and $139 \mathrm{H}$ isolates produced $\sim 10^{9} \mathrm{ID}_{50}$ units of prions per gram of brain tissue. In the brains of inoculated hamsters, each isolate produced similar amounts of $\mathrm{PrP}^{\mathrm{Sc}}$, which was converted to $\operatorname{PrP}$ 27-30 after limited proteolysis in vitro. The two prion isolates produced different kinetics and patterns of $\mathrm{PrP}^{\mathrm{Sc}}$ accumulation in Syrian hamsters and $\mathrm{Tg}(\mathrm{SHaPrP})$ mice, raising the possibility that these isolates are synthesized in different sets of cells in the central nervous system (CNS). Distinct isolates of prions might derive their biological properties from different conformations of $\mathrm{PrP}^{\mathrm{Sc}}$, post-translational chemical modifications, or noncovalently bound molecules (Prusiner 1991; Weissmann 1991).

\section{Results}

Synthesis of SHa prions in transgenic mice and Syrian hamsters

$\mathrm{Tg}(\mathrm{SHaPrP}) 81$ and nontransgenic control mice were inoculated with mixtures of RML Mo and Sc237 SHa prions (Table 1), and the incubation times were measured. The incubation times in Tg81 mice were determined by $\mathrm{SHa}$ prions alone even if the dose of Mo prions in the inoculum was $10^{4}$-fold greater than that of $\mathrm{SHa}$ prions. Non-Tg81 mice inoculated with $\sim 10^{6} \mathrm{ID}_{50}$ units of Mo prions had incubation times of $\sim 130$ days, whereas Tg81 mice inoculated with Mo prions had times of $\sim 180$ days (Table 1) (Prusiner et al. 1990).

A kinetic study was performed in which $\mathrm{SHa}$ prions were inoculated at increasing intervals after the inoculation of Mo prions (Table 2A). Again, the scrapie incubation times in $\mathrm{Tg} 81$ mice were determined by the $\mathrm{SHa}$ prions alone. No influence of SHa prions on the incubation times in non- $\mathrm{Tg} 81$ mice inoculated with Mo prions could be discerned (Table 2B).

To extend the experiments with $\mathrm{SHa}$ and Mo prions, Syrian hamsters were challenged with Sc237 prions at increasing intervals after the inoculation with $139 \mathrm{H}$ prions (Table 3). The scrapie incubation times were determined only by the Sc237 prions and, thus, were independent of the $139 \mathrm{H}$ prions. Even if the $139 \mathrm{H}$ prions were inoculated as much as 63 days before the inoculation with Sc237 prions, the incubation time was the same as that for animals inoculated with Sc237 prions alone. These results contrast with those reported by others where mouse isolates with long incubation times inoculated prior to short incubation time isolates produced long incubation times. Such observations were interpreted as competition among isolates for replication sites (Dickinson et al. 1972; Kimberlin and Walker 1985).

\section{Biochemical and biological properties} of two prion isolates

Because one infectious unit of Sc237 prions causes disease in hamsters $\sim 140$ days after inoculation (Marsh and Kimberlin 1975; Kimberlin and Walker 1977; Prusiner et

Table 2. Scrapie incubation times in $\operatorname{Tg}(S H a P r P) 81$ mice inoculated with Sc237 SHa prions at various intervals after inoculation with Mo prions

\begin{tabular}{|c|c|c|c|c|}
\hline \multirow{2}{*}{$\begin{array}{l}\text { Time of } \\
\text { inoculation } \\
\text { with SHa } \\
\text { prions }^{\mathrm{a}} \text { (day) }\end{array}$} & \multirow[b]{2}{*}{ Number } & \multicolumn{2}{|c|}{ Incubation time } & \multirow{2}{*}{$\begin{array}{l}\text { Interval between } \\
\text { inoculation with } \\
\text { SHa prions } \\
\text { and illness (day) }\end{array}$} \\
\hline & & \multicolumn{2}{|c|}{ (days \pm S.E.M.) } & \\
\hline \multicolumn{5}{|c|}{ A. $\mathrm{Tg}(\mathrm{SHaPr}) 81$ mice } \\
\hline 0 & 10 & $76 \pm 2$ & $79 \pm 1$ & 76 \\
\hline 1 & 3 & $79 \pm 4$ & $81 \pm 5$ & 78 \\
\hline 10 & 13 & $86 \pm 1$ & $90 \pm 2$ & 76 \\
\hline 30 & 2 & $97 \pm 0$ & $102 \pm 2$ & 67 \\
\hline 60 & 11 & $140 \pm 2$ & $146 \pm 2$ & 80 \\
\hline 100 & 12 & $169 \pm 2$ & $175 \pm 2$ & 69 \\
\hline$-^{\mathrm{b}}$ & 20 & $194 \pm 4$ & $200 \pm 3$ & \\
\hline \multicolumn{5}{|c|}{ B. Nontransgenic 81 mice } \\
\hline 0 & 14 & $138 \pm 3$ & $154 \pm 3$ & 138 \\
\hline 1 & 4 & $128 \pm 6$ & $141 \pm 2$ & 127 \\
\hline 10 & 12 & $138 \pm 3$ & $154 \pm 4$ & 128 \\
\hline 30 & 6 & $121 \pm 4$ & $139 \pm 3$ & 91 \\
\hline 60 & 15 & $136 \pm 3$ & $156 \pm 4$ & 76 \\
\hline
\end{tabular}

${ }^{a}$ All mice were inoculated with $\sim 10^{6} \mathrm{ID}_{50}$ units of Mo prions at day 0 and with $\sim 10^{7} \mathrm{ID}_{50}$ units of Sc237 SHa prions at the day designated.

${ }^{\mathrm{b}}$ No SHa prions inoculated. 
Table 3. Scrapie incubation times in Syrian hamsters inoculated with Sc237 prions at various intervals after inoculation with $139 \mathrm{H}$ prions

\begin{tabular}{|c|c|c|c|c|}
\hline \multirow{2}{*}{$\begin{array}{l}\text { Time of } \\
\text { inoculation } \\
\text { with Sc237 } \\
\text { prions }^{\mathbf{a}} \text { (day) }\end{array}$} & \multirow[b]{2}{*}{ Number } & \multicolumn{2}{|c|}{ Incubation time } & \multirow{2}{*}{$\begin{array}{l}\text { Interval between } \\
\text { inoculation with } \\
\text { Sc } 237 \text { and onset } \\
\text { of illness (days) }\end{array}$} \\
\hline & & $\begin{array}{l}\text { illness } \\
\text { |days } \pm\end{array}$ & $\begin{array}{l}\text { death } \\
\text { S.E.M.) }\end{array}$ & \\
\hline 0 & 5 & $85 \pm 3$ & $94 \pm 2$ & 85 \\
\hline 1 & 8 & $81 \pm 2$ & $91 \pm 1$ & 80 \\
\hline 10 & 7 & $85 \pm 4$ & $94 \pm 3$ & 75 \\
\hline 28 & 5 & $107 \pm 2$ & $120 \pm 3$ & 79 \\
\hline 63 & 6 & $151 \pm 0$ & $178 \pm 2$ & 88 \\
\hline$-{ }^{b}$ & 6 & $159 \pm 1$ & $185 \pm 3$ & \\
\hline
\end{tabular}

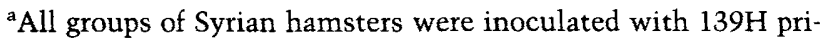
ons on day 0 .

${ }^{b}$ No Sc237 prions inoculated.

al. 1982b|, we considered the possibility that $139 \mathrm{H}$ prions were produced as a consequence of the defective synthesis of Sc237 prions. To assess this possibility, hamsters were inoculated with $139 \mathrm{H}$ prions and sacrificed 172 days after inoculation, and the concentration of infectious prion particles was measured by end-point titrations. There was no difference between prion titers in $10 \%$ (wt/vol) brain homogenates prepared from Syrian hamsters with clinical signs of scrapie after inoculation with either Sc237 (Prusiner et al. 1982b) or $139 \mathrm{H}$ prions. Prion titers $\left(\log \mathrm{ID}_{50} \mathrm{U} / \mathrm{ml} \pm\right.$ S.E.M.) of $8.1 \pm 0.33$, $8.6 \pm 0.45$, and $7.8 \pm 0.30$ were found by end-point titrations for three brain extracts from hamsters inoculated with $139 \mathrm{H}$ prions. In Figure 1, results from end-point titrations of $139 \mathrm{H}$ and Sc237 in Syrian hamsters are plotted-the reciprocal of the incubation time as a function of the $\log _{10}$ of the dose. The slopes of the two lines are clearly different. A comparison of any two doses of $139 \mathrm{H}$ gives a larger change in incubation time than those of Sc237.

Previous studies had shown an excellent correlation between $\mathrm{PrP}^{\mathrm{Sc}}$ concentrations and Sc237 prion titers (McKinley et al. 1983; Jendroska et al. 1991). As expected, we found that the concentration of $\operatorname{PrP}^{\mathrm{Sc}}$ in brains of terminally ill hamsters infected with $139 \mathrm{H}$ was similar to that with Sc237. Two different brain extracts prepared from Syrian hamsters with clinical scrapie after inoculation with Sc237 contained 70 and $80 \mu \mathrm{g}$ of $\operatorname{PrP}^{\mathrm{Sc}}$ / gram of protein, whereas four different extracts from hamsters inoculated with $139 \mathrm{H}$ had $72,86,84$, and $83 \mu \mathrm{g}$ of $\mathrm{PrP}^{\mathrm{Sc}} /$ gram of protein.

To facilitate purification on a small scale, a discontinuous sucrose gradient ultracentrifugation (Prusiner et al. 1982a) was replaced by ultrafiltration with a membrane of $300-\mathrm{kD}$ exclusion limit. The ultrafiltration was operated in a continuous dilution mode, that is, the volume lost in the course of the filtration was continuously replaced by the addition of fresh buffer. The prion rods were retained by the membrane, whereas most proteins, peptides, and other molecules with molecular mass $<300 \mathrm{kD}$ passed through the filter. After $\sim 1000$-fold dilution, the ultrafiltration was terminated, and the retentate was concentrated and analyzed by SDS-PAGE (Fig. 2A). Three major bands were found by silver staining: They correspond to $\operatorname{PrP} 27-30$ with varying amounts of $\mathrm{N}$-linked oligosaccharides (Oesch et al. 1985; Taraboulos et al. 1990a). The ultrafiltration procedure yields PrP 2730 of a purity similar to that obtained with sucrose gradients (Prusiner et al. 1982b, 1983); in the silver-stained lanes in Figure 2A, no components other than PrP 27-30 are visible. $\operatorname{PrP} 27-30$ is used to designate the proteaseresistant portion of $\mathrm{PrP}^{\mathrm{Sc}}$; the amino-terminal $\sim 67$ amino acids of $\mathrm{PrP}^{\mathrm{Sc}}$ are hydrolyzed when $\operatorname{PrP} 27-30$ is generated by limited proteolysis (McKinley et al. 1983; Prusiner et al. 1991).

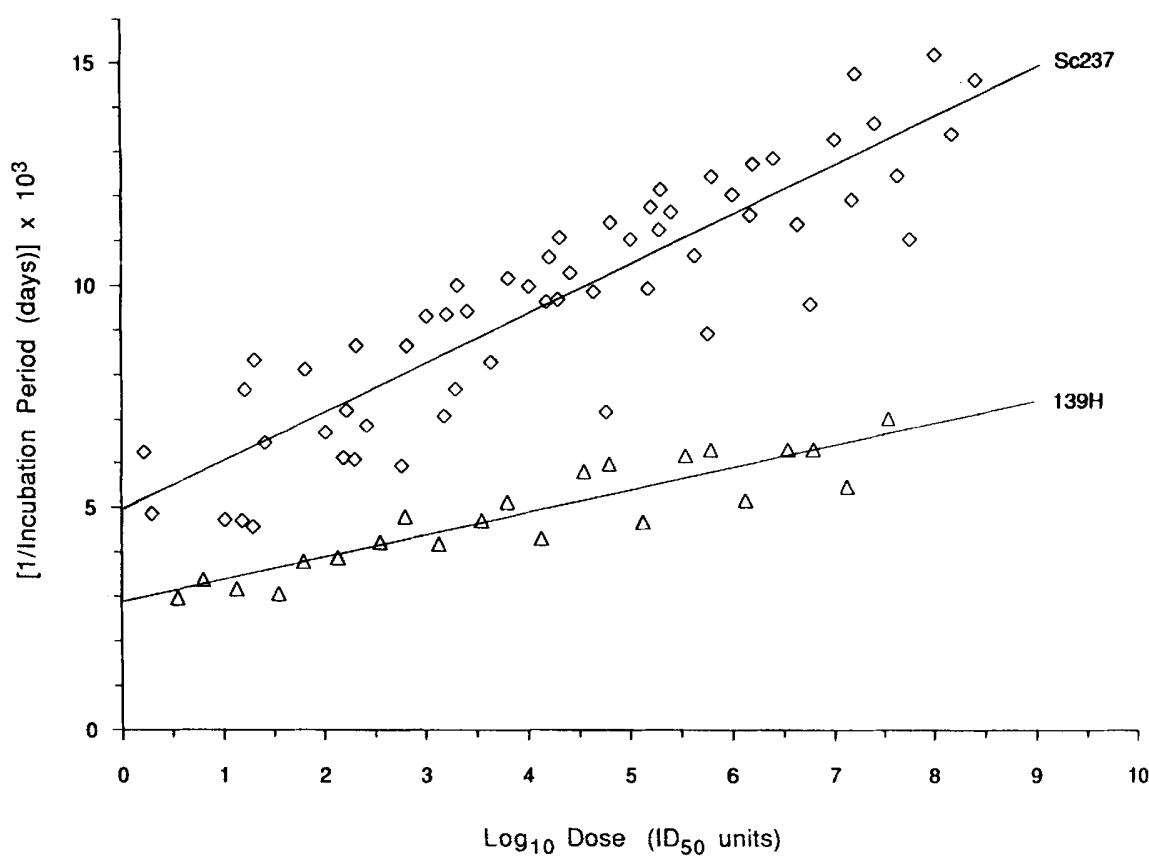

Figure 1. Scrapie incubation times plotted as a function of the dose of inoculum for two distinct prion isolates. The $\log _{10}$ dose, which is calculated from the titer $\times$ dilution, is on the $x$-axis; the reciprocal of incubation time is on the $y$-axis. The curves were fitted by linear regression analysis. Sc237 regression coefficient $=0.88$, slope $=1.11$, and $y$ intercept $=4.88 ; \quad 139 \mathrm{H}$ regression coefficient $=0.91$, slope $=0.51$, and $y$ intercept $=2.82$. 


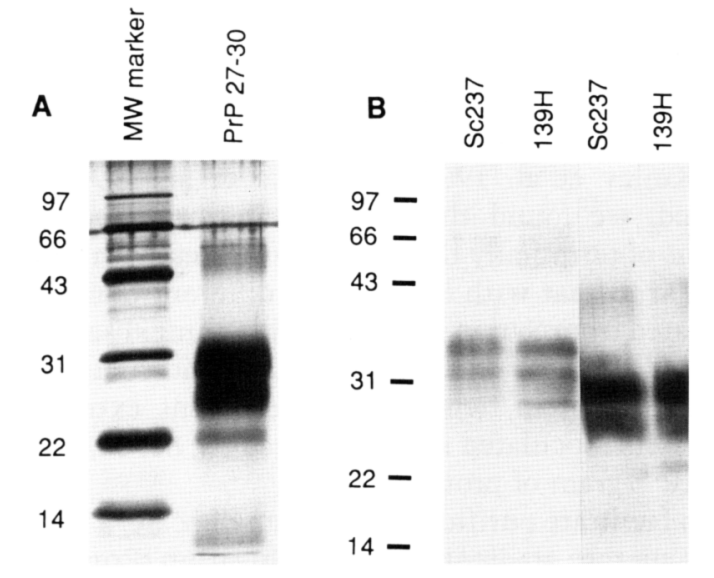

Figure 2. Scrapie prion proteins in brains of Syrian hamsters inoculated with Sc237 or $139 \mathrm{H}$ prions. (A) Analysis of $139 \mathrm{H}$ prion rods from Syrian hamster brains after purification by ultrafiltration. A 12\% SDS-polyacrylamide gel (Laemmli 1970) was stained with silver (Turk et al. 1988). (Lane 1) Molecular weight markers; (lane 2) denatured prion rods purified from $139 \mathrm{H}$-infected hamster brain. The three bands represent $\operatorname{Pr} P$ 27-30 with 2, 1, and no $N$-linked oligosaccharides. $(B)$ Western blot of brain homogenates and purified PrP 27-30. PrP was visualized with the monoclonal antibody 13A5 (Barry and Prusiner 1986). (Lanes 1,2) $50 \mu \mathrm{g}$ of brain extract from Syrian hamsters infected with $\mathrm{Sc} 237$ and $139 \mathrm{H}$, respectively. The three bands represent the double, single, and non- $N$-linked glycosylated forms of PrP 33-35. (Lanes 3,4) Purified prion rods purified from the brains of hamsters infected with $\mathrm{Sc} 237$ and $139 \mathrm{H}$, respectively. The three bands represent the variations in extent of glycosylation for PrP 27-30, as described above.

We compared $\operatorname{PrP}^{\mathrm{Sc}}$ and PrP 27-30 from the brains of hamsters infected with Sc237 and $139 \mathrm{H}$. In Figure $2 \mathrm{~B}$ a Western blot of brain homogenate from terminally ill Syrian hamsters infected with either Sc237 or $139 \mathrm{H}$ is shown. In lanes 1 and 2, the patterns of PrP immunoreactivity for Sc237 and $139 \mathrm{H}$ were indistinguishable. With both isolates, double, single, and nonglycosylated forms of $\operatorname{PrP}$ were found. No difference in molecular mass, glycosylation, and immunogenicity could be discerned between $\operatorname{PrP}$ molecules in the two isolates. In lanes 3 and 4, purified PrP 27-30 from Sc237 and 139H is shown; again, no differences could be discerned from the two isolates.

\section{Phenotypic properties of prion isolates upon passage in different hamster species}

To assess the variation and distribution of scrapie incubation for the two $\mathrm{SHa}$ prion isolates, we assembled the data from 48 Syrian hamsters infected with Sc237 prions. These animals had mean incubation periods from inoculation to onset of illness of $77 \pm 1$ (S.E.M.) days and to death of $89 \pm 2$ (S.E.M.) days, whereas, 94 Syrian hamsters inoculated with $139 \mathrm{H}$ prions developed neurologic dysfunction at $167 \pm 1$ (S.E.M. and died at $206 \pm 2$ (S.E.M.) days. For Sc 237 prions, the hamsters died $\sim 12$ days after the onset of illness while those hamsters with $139 \mathrm{H}$ prions showed a progressive neurologic disorder lasting $\sim 39$ days. Although other investigators state that $139 \mathrm{H}$ causes disease in Syrian hamsters in $\sim 130$ days (Kimberlin et al. 1987b, 1989), we have not been able to confirm their observations. They have not reported survival times so no objective comparison can be made.

Because the homology among the PrP gene products of three species of hamsters exceeds $96 \%$ (Lowenstein et al. 1990), we studied the behavior of two scrapie isolates in these animals. In Syrian hamsters, intracerebral inoculation of $\sim 10^{7} \mathrm{ID}_{50}$ units of $139 \mathrm{H}$ (Table 4) requires almost 100 days longer to produce clinical signs of scrapie than does the $\mathrm{Sc} 237$ isolate. $139 \mathrm{H}$ prions inoculated into Armenian hamsters required $\sim 40$ days longer to produce disease than did Sc237 (Table 4). Upon passage of the two isolates in Chinese hamsters, we found that the phenotypes of the two scrapie prion isolates were reversed: $139 \mathrm{H}$ prions required 100 days less than that needed for Sc237 prions to produce clinical signs of scrapie (Table 4). Furthermore, the duration of illness in Chinese hamsters for $139 \mathrm{H}$ is $\sim 15$ days in contrast to Syrian hamsters, where the animals deteriorate progressively over a period of $\sim 40$ days. Because of the species barriers between the three hamster species presumably owing to differences in PrP sequence (Lowenstein et al. 1990), it was necessary to acquire data on prions passaged repeatedly in each species and passaged directly from Syrian to Chinese hamsters (Table 4A). Although the incubation times are longer, as expected upon crossing the species barrier, the relative characteristics of the changes attendant with passage of each scrapie isolate in different hamster species are similar.

After passage of Sc237 and $139 \mathrm{H}$ prions into Chinese hamsters, these isolates were inoculated into Syrian hamsters to determine the incubation times for each isolate. $139 \mathrm{H}$ prions required $\sim 100$ days longer to produce clinical signs of scrapie than Sc237, showing that the phenotypic differences between the two strains are distinct for any given host (Table 4A). Although the difference in incubation times of 100 days for the two isolates is similar to that noted above for the Syrian to Syrian passage, the incubation times are longer owing to crossing of species barrier again. A second passage of either Sc 237 or $139 \mathrm{H}$ in Syrian hamsters demonstrates that this is the case. Results similar to those with Chinese hamsters were obtained when Sc237 and $139 \mathrm{H}$ prions were passaged into Armenian hamsters (Table 4B). On first passage, the incubation time in Armenian hamsters was longer for $\mathrm{Sc} 237$ than for $139 \mathrm{H}$ prions; and on subsequent passage, the incubation times for both prions were similar. Passage of the two prion isolates from Armenian back into Syrian hamsters showed that each strain retained its original properties: $139 \mathrm{H}$ required $\sim 100$ days longer than Sc237 for the appearance of clinical signs of scrapie (Table 4B).

\section{Characteristics of SHa prion isolates passaged in transgenic mice}

We also studied the behavior of the two scrapie isolates $\mathrm{Sc} 237$ and $139 \mathrm{H}$ prions in $\mathrm{Tg}(\mathrm{SHaPrP}) 81$ and $\mathrm{Tg}$ - 
Table 4. Scrapie incubation times for Syrian, Armenian, and Chinese hamsters inoculated with either Sc237 or $139 H$ prions

\begin{tabular}{|c|c|c|c|c|c|c|c|}
\hline \multirow[b]{2}{*}{ Inoculum ${ }^{a}$} & \multirow[b]{2}{*}{ Hamster $^{\mathrm{b}}$} & \multicolumn{3}{|c|}{$\operatorname{Sc} 237^{\mathrm{c}}$} & \multicolumn{3}{|c|}{$139 \mathrm{H}$} \\
\hline & & number ${ }^{d}$ & \multicolumn{2}{|c|}{ (days \pm S.E.M.) } & number ${ }^{d}$ & \multicolumn{2}{|c|}{ (days \pm S.E.M.) } \\
\hline \multicolumn{8}{|c|}{ A. Chinese hamsters } \\
\hline $\mathrm{SHa} \rightarrow \mathrm{SHa}$ & Syrian & 48 & $77 \pm 1$ & $89 \pm 2$ & 94 & $167 \pm 1$ & $206 \pm 2$ \\
\hline $\mathrm{SHa} \rightarrow \mathrm{SHa}$ & Chinese & 4 & $344 \pm 7$ & $358 \pm 16$ & 20 & $241 \pm 3$ & $284 \pm 3$ \\
\hline $\mathrm{SHa} \rightarrow \mathrm{CHa}$ & Chinese & 9 & $265 \pm 2$ & $274 \pm 3$ & 8 & $226 \pm 4$ & $241 \pm 7$ \\
\hline $\mathrm{CHa} \rightarrow \mathrm{CHa}$ & Chinese & 15 & $272 \pm 3$ & $307 \pm 6$ & 8 & $171 \pm 5$ & $181 \pm 11$ \\
\hline $\mathrm{SHa} \rightarrow \mathrm{CHa}$ & Syrian & 16 & $121 \pm 8$ & $133 \pm 6$ & 9 & $229 \pm 4$ & $274 \pm 7$ \\
\hline $\mathrm{CHa} \rightarrow \mathrm{SHa}$ & Syrian & 13 & $69 \pm 2$ & $79 \pm 5$ & 10 & $182 \pm 3$ & $194 \pm 4$ \\
\hline \multicolumn{8}{|c|}{ B. Armenian hamsters } \\
\hline $\mathrm{SHa} \rightarrow \mathrm{SHa}$ & Armenian & 4 & $174 \pm 1$ & $194 \pm 2$ & 7 & $146 \pm 1$ & $161 \pm 1$ \\
\hline $\mathrm{SHa} \rightarrow \mathrm{AHa}$ & Armenian & 8 & $128 \pm 3$ & $153 \pm 5$ & 4 & $153 \pm 0$ & $154 \pm 0$ \\
\hline $\mathrm{AHa} \rightarrow \mathrm{AHa}$ & Armenian & 16 & $125 \pm 2$ & $148 \pm 3$ & 8 & $165 \pm 3$ & $174 \pm 3$ \\
\hline $\mathrm{SHa} \rightarrow \mathrm{AHa}$ & Syrian & 14 & $113 \pm 2$ & $129 \pm 4$ & 7 & $214 \pm 7$ & $232 \pm 5$ \\
\hline
\end{tabular}

apassage history of the inoculum. (SHa) Syrian hamster; (AHa) Armenian hamster; (CHa) Chinese hamster.

becies of hamster inoculated intracerebrally.

'Some of the data for Sc237 prions in $A$ and $B$ are taken from Lowenstein et al. (1990).

${ }^{\mathrm{d}}$ Number of animals.

'Incubation period in days \pm S.E.

(SHaPrP)7 mice (Prusiner et al. 1990). The difference in incubation times for the two isolates was $\sim 35$ days in $\mathrm{Tg}(\mathrm{SHaPrP}) 81$ mice (Table 5A; Fig. 3A). In contrast, $\mathrm{Tg}$ (SHaPrP)7 mice had similar incubation times when inoculated with either Sc237 or $139 \mathrm{H}$ prions (Table 5B; Fig. 3B). Passage of Sc237 and $139 \mathrm{H}$ from transgenic mice into Syrian hamsters produced incubation times similar to those found upon repeated passage in Syrian hamsters (Tables 4 and 5). These observations argue that the phenotypic changes in scrapie incubation times for two prion isolates upon passage in $\mathrm{Tg}(\mathrm{SHaPrP})$ mice are modulated by the level of $\mathrm{SHaPrP}^{\mathrm{C}}$ expression. It is noteworthy that the duration of illness was considerably shorter in Syrian hamsters inoculated with $139 \mathrm{H}$ prions passaged through $\mathrm{Tg} 81$ or $\mathrm{Tg} 7$ mice compared with the original SHa inoculum (Table 5).

Only a few nontransgenic mice inoculated with Sc237 prions develop scrapie after a prolonged incubation period (Table 5C) (Scott et al. 1989), but those inoculated with $139 \mathrm{H}$ prions uniformly developed CNS disease at $\sim 500$ days. Passage of the Sc237 prions through Chinese hamsters to produce Chinese hamster $\operatorname{PrP}^{\mathrm{Sc}}\left(\mathrm{CHaPr}^{\mathrm{Sc}}\right)$ produced clinical scrapie in all of the CD-1 Swiss mice $\sim 325$ days after inoculation. Of note, the amino acid sequence of $\mathrm{CHaPrP}$ is more similar to MoPrP-A than SHaPrP (Lowenstein et al. 1990).

Table 5. Scrapie incubation times for transgenic mice and Syrian hamsters inoculated with either Sc237 or $139 \mathrm{H}$ prions

\begin{tabular}{|c|c|c|c|c|c|c|c|}
\hline \multirow[b]{3}{*}{ Inoculum } & \multirow[b]{3}{*}{ Animal $^{a}$} & \multicolumn{3}{|c|}{ Sc237 } & \multicolumn{3}{|c|}{$139 \mathrm{H}$} \\
\hline & & \multirow[b]{2}{*}{ number } & illness & death & \multirow[b]{2}{*}{ number } & illness & death \\
\hline & & & \multicolumn{2}{|c|}{ (days \pm S.E.M.) } & & \multicolumn{2}{|c|}{ (days \pm S.E.M.) } \\
\hline \multicolumn{8}{|c|}{ A. $\operatorname{Tg} 81$ mice } \\
\hline $\mathrm{SHa} \rightarrow \mathrm{SHa}$ & Syrian & 48 & $77 \pm 1$ & $83 \pm 2$ & 94 & $167 \pm 1$ & $206 \pm 2$ \\
\hline $\mathrm{SHa} \rightarrow \mathrm{SHa}$ & Tg81 & 22 & $75 \pm 2$ & $75 \pm 2$ & 19 & $110 \pm 2$ & $115 \pm 2$ \\
\hline $\mathrm{SHa} \rightarrow \mathrm{Tg} 81$ & Tg81 & 8 & $81 \pm 2$ & $83 \pm 3$ & 7 & $106 \pm 3$ & $110 \pm 3$ \\
\hline $\mathrm{SHa} \rightarrow \mathrm{Tg} 81$ & Syrian & 5 & $77 \pm 2$ & $91 \pm 2$ & 3 & $205 \pm 1$ & $214 \pm 3$ \\
\hline \multicolumn{8}{|c|}{ B. $\quad \operatorname{Tg} 7$ mice } \\
\hline $\mathrm{SHa} \rightarrow \mathrm{SHa}$ & $\operatorname{Tg} 7$ & 26 & $48 \pm 1$ & $51 \pm 1$ & 11 & $40 \pm 3$ & $42 \pm 3$ \\
\hline $\mathrm{SHa} \rightarrow \mathrm{Tg} 7$ & $\mathrm{Tg} 7$ & 6 & $54 \pm 1$ & $58 \pm 2$ & 6 & $59 \pm 2$ & $63 \pm 3$ \\
\hline $\mathrm{SHa} \rightarrow \mathrm{Tg} 7$ & Syrian & 11 & $81 \pm 1$ & $95 \pm 1$ & 7 & $181 \pm 6$ & $188 \pm 4$ \\
\hline \multicolumn{8}{|c|}{ C. Nontransgenic mice } \\
\hline $\mathrm{SHa} \rightarrow \mathrm{SHa}$ & non-Tg81 & 9 & $>700$ & & 11 & $499 \pm 15$ & $523 \pm 15$ \\
\hline $\mathrm{CHa} \rightarrow \mathrm{CHa}$ & CD-1 & 7 & $325 \pm 17$ & $346 \pm 1610$ & 10 & $>420$ & \\
\hline
\end{tabular}

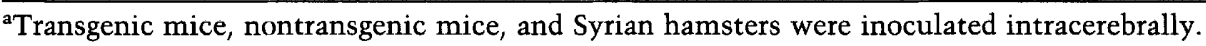



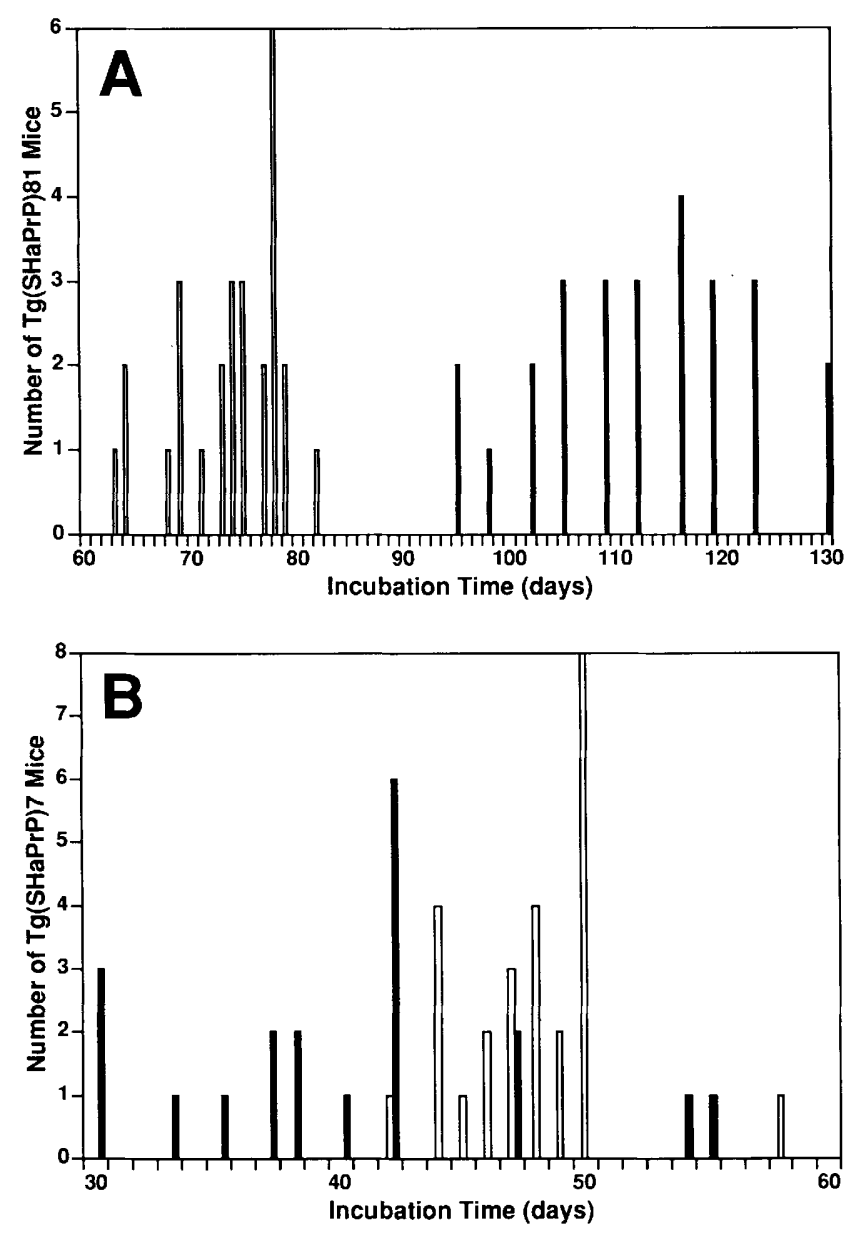

Figure 3. Incubation times for two distinct prion isolates in transgenic mice expressing the SHaPrP. $(A) \mathrm{Tg}(\mathrm{SHaPrP}) 81 ;(B)$ $\mathrm{Tg}(\mathrm{SHaPrP}) 7$ mice inoculated with $\mathrm{Sc} 237$ (open bars) or $139 \mathrm{H}$ (solid bars) prions.

\section{Correlation of vacuolation and $\operatorname{Pr} P^{S c}$ for two prion isolates}

In addition to incubation times, the distribution and amount of neuropil vacuolation have been used to define prion isolates (Fraser and Dickinson 1968, 1973). Consistent with this, vacuolation was coarser in gray matter and was found in all layers of the cerebral cortex of hamsters inoculated with $139 \mathrm{H}$ prions, whereas it was more delicate and subtle with Sc237 and was largely confined to layers 4-6 (Fig. 4). Figure 4, A and C, shows layer II of the cerebral cortex while Figure 4, B and D, shows layer IV. Shrinkage artifact around blood vessels and some cells (A) can be readily distinguished from disease-related vacuolation in the neuropil between neurons (B). In Figure 4, C and D, widespread vacuolation is evident along with increased cell number owing to proliferation of astrocytes and infiltration of microglia. Vacuolation was also present in the caudate nucleus and cerebellum of Syrian hamsters inoculated with $139 \mathrm{H}$ prions in contrast to those inoculated with $\mathrm{Sc} 237$, in which pathology was not significant in these structures (DeArmond et al.
1987). Reactive astrocytic gliosis and vacuolation colocalized with both isolates (Fig. 4). Additionally, amyloid plaques composed of SHaPrP were found in the same subpial, subependymal, and subcallosal locations with both $139 \mathrm{H}$ and Sc237 prions (DeArmond et al. 1985).

The regional distribution $\operatorname{PrP}^{S c}$ in the brains of Syrian hamsters was compared for $\mathrm{Sc} 237$ and $139 \mathrm{H}$ prions by use of "histoblots" immunostained with $\alpha$-PrP antibodies (Taraboulos et al. 1992) (Fig. 4). The histoblots were pretreated with proteinase $\mathrm{K}$ to eliminate $\mathrm{PrPC}$ and then exposed to $\mathrm{Gdn}-\mathrm{HCl}$ to denature $\operatorname{PrP}^{\mathrm{Sc}}$ and thereby enhance its immunoreactivity. With $139 \mathrm{H}$ prions, $\operatorname{PrP}{ }^{\mathrm{Sc}}$ was distributed more diffusely in the gray and white matter than with Sc237. For example, $\operatorname{PrP}^{\mathrm{Sc}}$ was uniformly distributed in all layers in the neocortex with $139 \mathrm{H}$ prions, whereas it was mostly confined to layers 4-6 in those infected with Sc237 (Fig. 4). Immunostaining of the caudate nucleus was intense in $139 \mathrm{H}$-inoculated hamsters, but it was absent with Sc237 (data not shown). These results demonstrate that vacuolation, reactive astrocytic gliosis, and $\mathrm{PrP}^{\mathrm{Sc}}$ colocalize in both $139 \mathrm{H}$ and Sc237 scrapie. Therefore, while the distribution of $\operatorname{PrP}^{\mathrm{Sc}}$ and the accompanying neuropathologic changes are different for the two scrapie prion isolates, the relationship between $\mathrm{PrP}^{\mathrm{Sc}}$ deposition and neuropathologic lesions remained constant.

\section{Kinetics and patterns of $\operatorname{Pr} P^{S c}$ accumulation in Syrian hamsters}

To extend observations on the patterns of $\operatorname{PrP}^{S c}$ accumulation, the kinetics of $\mathrm{PrP}^{\mathrm{Sc}}$ deposition in the brains of Syrian hamsters were compared for Sc237 and $139 \mathrm{H}$ prions. Seven to 14 days after unilateral intrathalamic inoculation with Sc237 prions, $\mathrm{PrP}^{\mathrm{Sc}}$ became detectable at the inoculation site (Fig. 5A). Spread of $\mathrm{PrP}^{\mathrm{Sc}}$ from this region occurred by at least two routes. Spread to the neocortex appeared to be by axonal transport, as the most intense immunostaining for $\operatorname{PrP}^{\mathrm{Sc}} 65$ days postinoculation occurred in neocortical layers 4 and 6 , the main termination sites of thalamocortical projections (Fig. 4; Fig. 5A: 65 days). Spread of $\mathrm{PrP}^{\mathrm{Sc}}$ to the contralateral thalamus and the septum, which was detectable by 21 and 28 days, respectively, was probably not by axonal transport because there are few, if any, direct neuroanatomical interconnections between the two lateral halves of the thalamus or between the thalamus and the septum. Histoblots showed that the spread of $\operatorname{PrP}^{\mathrm{Sc}}$ in the thalamus was not by a continuous, radially directed process starting from the initial site of $\operatorname{PrP}^{\mathrm{Sc}}$ accumulation but, rather, by an apparently discontinuous process in which $\operatorname{PrP}^{\mathrm{Sc}}$ was found within identical nuclei in the contralateral thalamus (Fig. 5A, 21, 28, 35 days). By 35 days, $\operatorname{PrP}^{\mathrm{Sc}}$ was distributed symmetrically in the thalamus within homologous nuclei. This pattern of accumulation suggests that $\mathrm{PrP}^{\mathrm{Sc}}$ released from specific populations of neurons into the extracellular space has a propensity to target to homologous contralateral neurons. That $\mathrm{PrP}^{\mathrm{Sc}}$ can be carried in the extracellular space from the unilaterally inoculated thalamus to the same contra- 

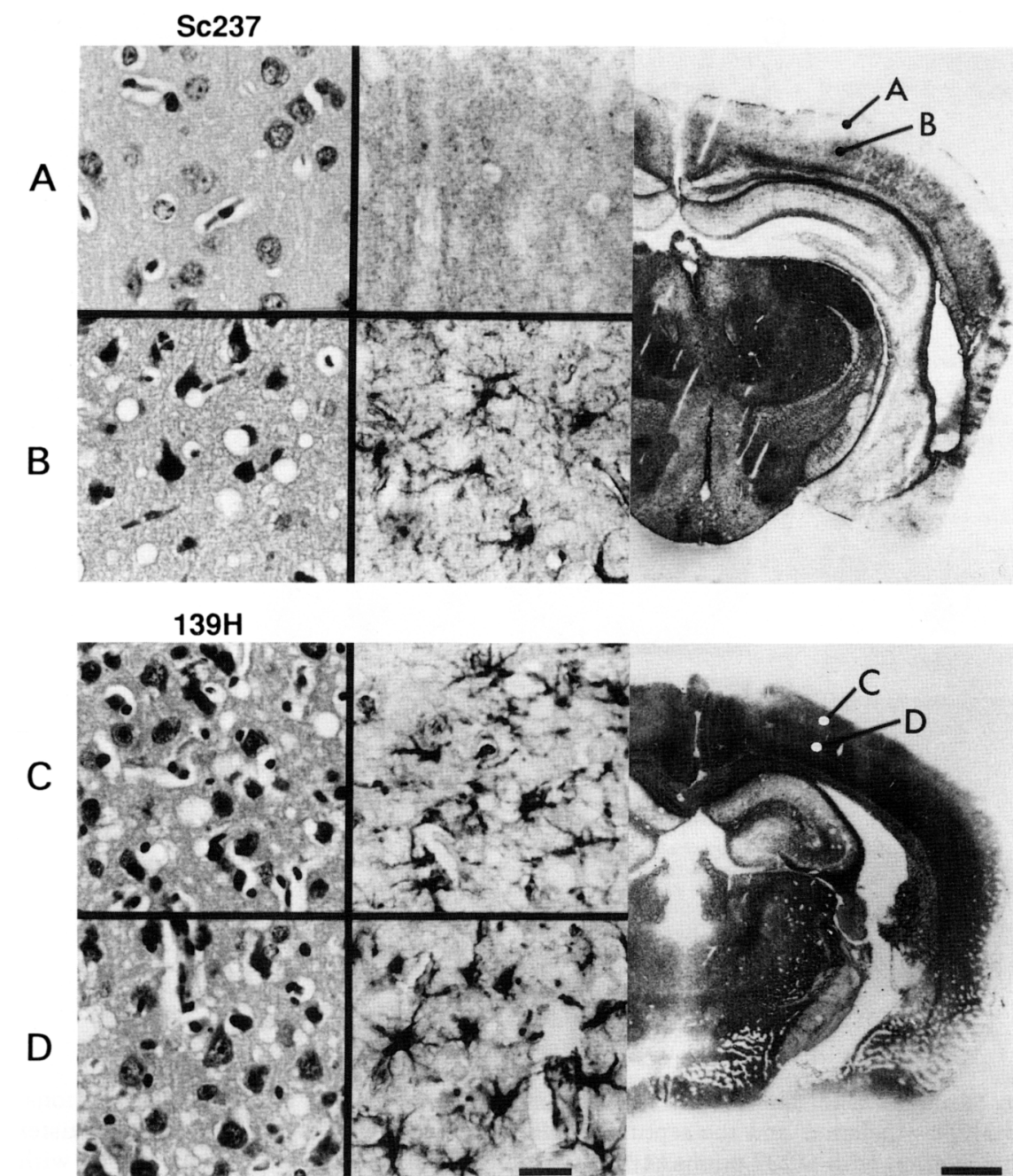

$H \& E$
GFAP
Histoblot
Figure 4. Colocalization of neuropathological changes and $\operatorname{PrP}^{\mathrm{Sc}}$ in the brains of Syrian hamsters with clinical signs of scrapie after inoculation with either Sc237 (70 days postinoculation) or $139 \mathrm{H}$ prions (168 days postinoculation). (Left panels) Vacuolation assessed on brain sections stained with hematoxylin and eosin (H \& E). (Middle panels) Reactive astrocytic gliosis demonstrated by immunohistochemistry with antibodies to glial fibrillary acidic protein (GFAP). (Right panels) Location of $\mathrm{PrP}^{\mathrm{Sc}}$ revealed by histoblots of coronal brain sections at the level of the thalamus and hippocampus. The lettered black and white dots in the histoblots indicate the approximate locations in the cerebral cortex of the photomicrographs in the left and middle panels. Note the difference in magnification: Bar on histoblot, $1 \mathrm{~mm}$; bar on histologic sections, $50 \mu \mathrm{m}$. With Sc237 prions, little or no PrP $\mathrm{Pc}^{\mathrm{Sc}}$, vacuolation or reactive gliosis was present in the outer layers of the cerebral cortex $|A|$, whereas all were present in the inner half $(B)$, consistent with an earlier immunohistochemical study (DeArmond et al. 1987). In contrast with $139 \mathrm{H}$ prions, $\mathrm{PrP}^{\mathrm{Sc}}$ accumulated in all layers of the neocortex $(C, D)$, as did vacuolation and reactive astrocytic gliosis. Increased cellularity in regions with vacuolation, particularly with $139 \mathrm{H}$, is due in part to astrocyte proliferation and infiltration by microglial cells. lateral structures was supported by the fate of unilateral injections of India ink (50 $\mu$ l of a 1: 10 dilution). The ink was distributed rapidly and symmetrically to those subpial, subependymal, and subcallosal regions where $\operatorname{PrP}$ amyloid plaques occur (data not shown).

Specific targeting of $\mathrm{PrP}^{\mathrm{Sc}}$ to distant neurons was also evident in the septum. In this case, $\mathrm{PrP}^{\mathrm{Sc}}$ appeared to be transported by the cerebrospinal fluid (CSF). As early as 7 days postinoculation, $\mathrm{PrP}^{\mathrm{Sc}}$ was detected in the walls of the lateral ventricles, which form the lateral surface of the septum and the medial surface of the caudate nucleus (Fig. 5A). While a portion of this $\mathrm{PrP}^{\mathrm{Sc}}$ could have been derived from the Sc237 inoculum, the majority appears to originate from newly formed $\mathrm{PrP}^{\mathrm{Sc}}$ in the thalamus because the thickness and intensity of immunostaining at the ventricular wall increased over the next 3 weeks. By 28 days, $\operatorname{PrP}^{\mathrm{Sc}}$ was detectable in the medial septal nucleus and the diagonal band of Broca. By day 35 , the medial septal region was strongly immunopositive for $\operatorname{Pr} \mathrm{P}^{\mathrm{Sc}}$, and by day $70, \operatorname{PrP}^{\mathrm{Sc}}$ was present in both the medial and lateral septal regions. These results argue that some of the newly formed $\mathrm{PrP}^{\mathrm{Sc}}$ in the thalamus is released into the ventricles and that the septum and basal forebrain region (diagonal band of Broca) are specifically targeted. Infection of the septum by the CSF appears to be unique to this structure because the caudate nucleus, whose walls also contained $\mathrm{PrP}^{\mathrm{Sc}}$ by 7-14 days, did not begin to accumulate $\operatorname{PrP}^{\mathrm{Sc}}$ until after 63 days (Jendroska et al. 1991). Specific targeting of the medial septal and diagonal band of Broca neurons by de novosynthesized $\mathrm{PrP}^{\mathrm{Sc}}$ supports the hypothesis that particular populations of neurons specify the behavior of $\operatorname{PrP}{ }^{S c}$.

Syrian hamsters inoculated in the thalamus with $139 \mathrm{H}$ prions have scrapie incubation times of $\sim 165$ days, and the kinetics of $\operatorname{PrP}^{\mathrm{Sc}}$ accumulation were correspondingly slower (Fig. 5B). PrP $\mathrm{P}^{\mathrm{Sc}}$ was barely detectable in the thalamus at 40 days, indicating a significant delay in its appearance in contrast to hamsters inoculated with Sc237. There was little or no accumulation of $\operatorname{PrP}^{\mathrm{Sc}}$ in the walls of the ventricles and no evidence for spread of prions through CSF routes with $139 \mathrm{H}$ prions. While $\mathrm{PrP}^{\mathrm{Sc}}$ accumulated in the septum late in $139 \mathrm{H}$ scrapie, it 


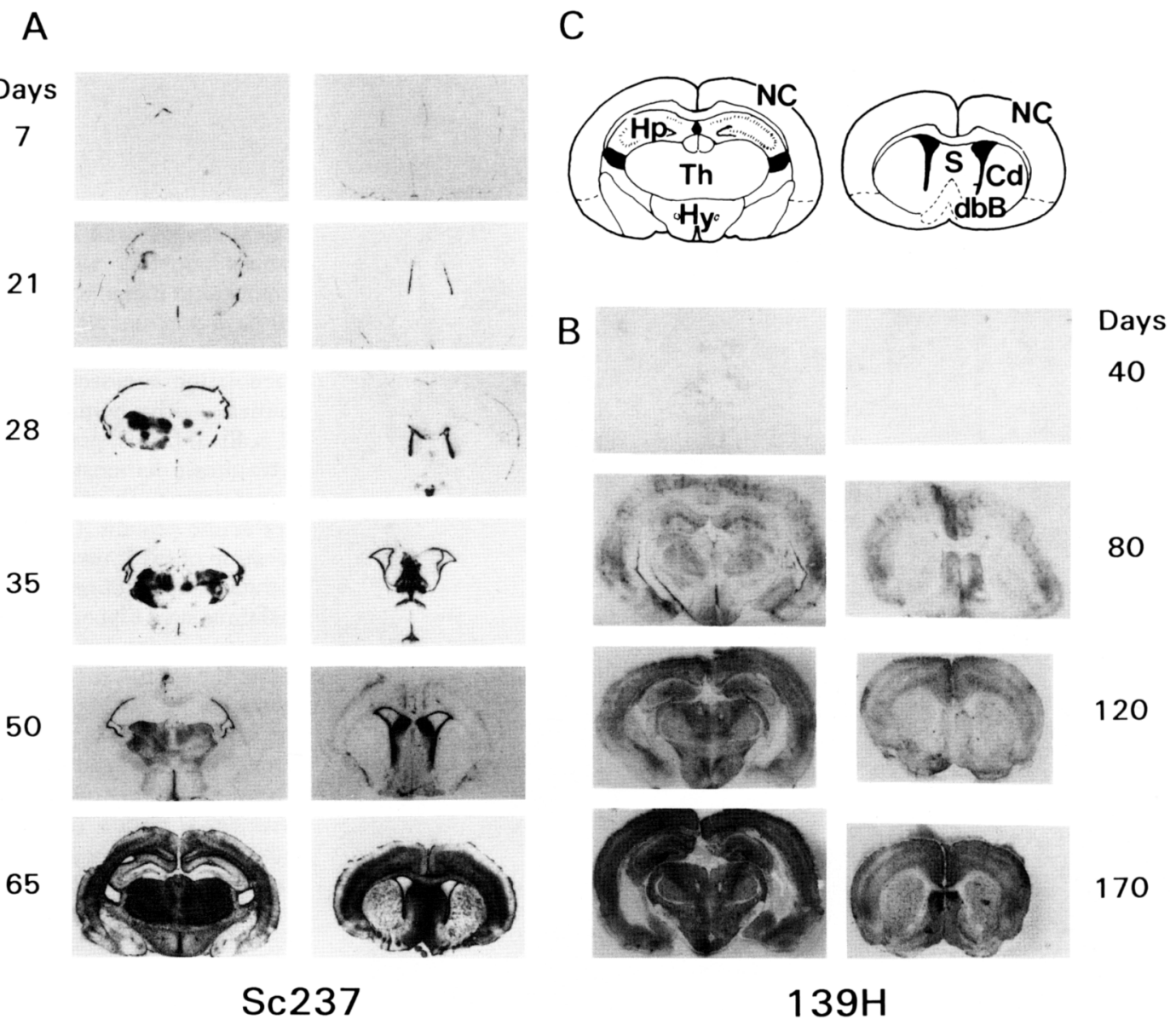

Figure 5. Kinetics of $\mathrm{PrP}^{\mathrm{Sc}}$ accumulation in Syrian hamster brains after inoculation with either Sc237 or $139 \mathrm{H}$ scrapie prions. Cryostat coronal sections through the hippocampus-thalamus and the septum-caudate nucleus were taken from Syrian hamster brains at $7,21,28,35,50$, and 65 days after inoculation with Sc237 prions $(A)$ or at 40,80, 120, and 170 days after inoculation with $139 \mathrm{H}$ prions $(B)$. The prion inoculum contained $\sim 10^{7} \mathrm{ID}_{50}$ units, and $50 \mu \mathrm{l}$ was inoculated intracerebrally. Histoblots were stained for $\mathrm{PrP}^{\mathrm{Sc}}$ with the PrP antiserum R073. (C) Diagrams identify major anatomical structures seen in coronal sections: $(\mathrm{NC})$ neocortex; $(\mathrm{Hp})$ hippocampus; (Th) thalamus; (Hy) hypothalamus; (S) septum; (Cd) caudate; (dbB) diagonal band of Broca.

was absent in the early phase of the incubation period. The relative concentrations of $\mathrm{PrP}^{\mathrm{Sc}}$ from 80 to 160 days, based on intensity of immunostaining, indicated a substantially slower rate of accumulation of $139 \mathrm{H} \mathrm{Pr}^{\mathrm{sc}}$ compared with $\mathrm{Sc} 237 \mathrm{PrP}^{\mathrm{Sc}}$. When clinical signs first appeared, more brain regions had accumulated $\mathrm{PrP}^{\mathrm{Sc}}$ by 165 days in hamsters inoculated with $139 \mathrm{H}$ prions than those inoculated with Sc237 at 75 days.

\section{Kinetics and patterns of $P_{r} P^{S c}$ accumulation in transgenic mice}

Interpretation of the results of Sc237 and $139 \mathrm{H}$ prions in Syrian hamsters with respect to the kinetics and patterns of $\operatorname{PrP}^{\mathrm{Sc}}$ accumulation (Figs. 4 and 5) is complicated because scrapie incubation times were so markedly different (Table 4). To circumvent this problem, we examined the kinetics of $\operatorname{PrP}$ accumulation in $\mathrm{Tg}(\mathrm{SHaPrP}) 7$ mice because scrapie incubation times were $\sim 50$ days with both $139 \mathrm{H}$ and Sc237 prions (Fig. 3B).
The differences in $\operatorname{PrP}^{\mathrm{Sc}}$ kinetics and neuroanatomic distribution were even more striking in $\mathrm{Tg}(\mathrm{SHaPrP}) 7$ mice (Fig. 6). At $\sim 49$ days, $\operatorname{PrP}^{\mathrm{Sc}}$ was found in most thalamic nuclei with $139 \mathrm{H}$ prions, whereas it was confined to the lateral-ventral tier of thalamic nuclei with Sc237 prions (Figs. 6 and 7). Also, by day 49, high concentrations of $\mathrm{PrP}^{\mathrm{Sc}}$ were found in Ammon's horn of the hippocampus and in the neocortex with $139 \mathrm{H}$, whereas little or no $\mathrm{PrP}^{\mathrm{Sc}}$ was detected in either structure with Sc237 prions. There were also striking differences in the distribution of $\operatorname{PrP}^{\mathrm{Sc}}$ in the brain stem, particularly in the reticular formation of the midbrain, pons and medulla, but also in the vestibular nuclei and the deep cerebellar nuclei (Fig. 8). An intense $\mathrm{PrP}^{\mathrm{Sc}}$ accumulation in the corpus callosum was found with $139 \mathrm{H}$ prions while little or none was found with Sc237 prions. Other white matter tracts were less immunopositive with $139 \mathrm{H}$.

The patterns of $\operatorname{PrP}{ }^{\mathrm{Sc}}$ accumulation with $\mathrm{Sc} 237$ and $139 \mathrm{H}$ prions were similar in two respects. First, $\operatorname{Pr} \mathrm{P}^{\mathrm{Sc}}$ accumulation in $\mathrm{Tg}(\mathrm{SHaPrP}) 7$ mice did not begin at the 
Sc237

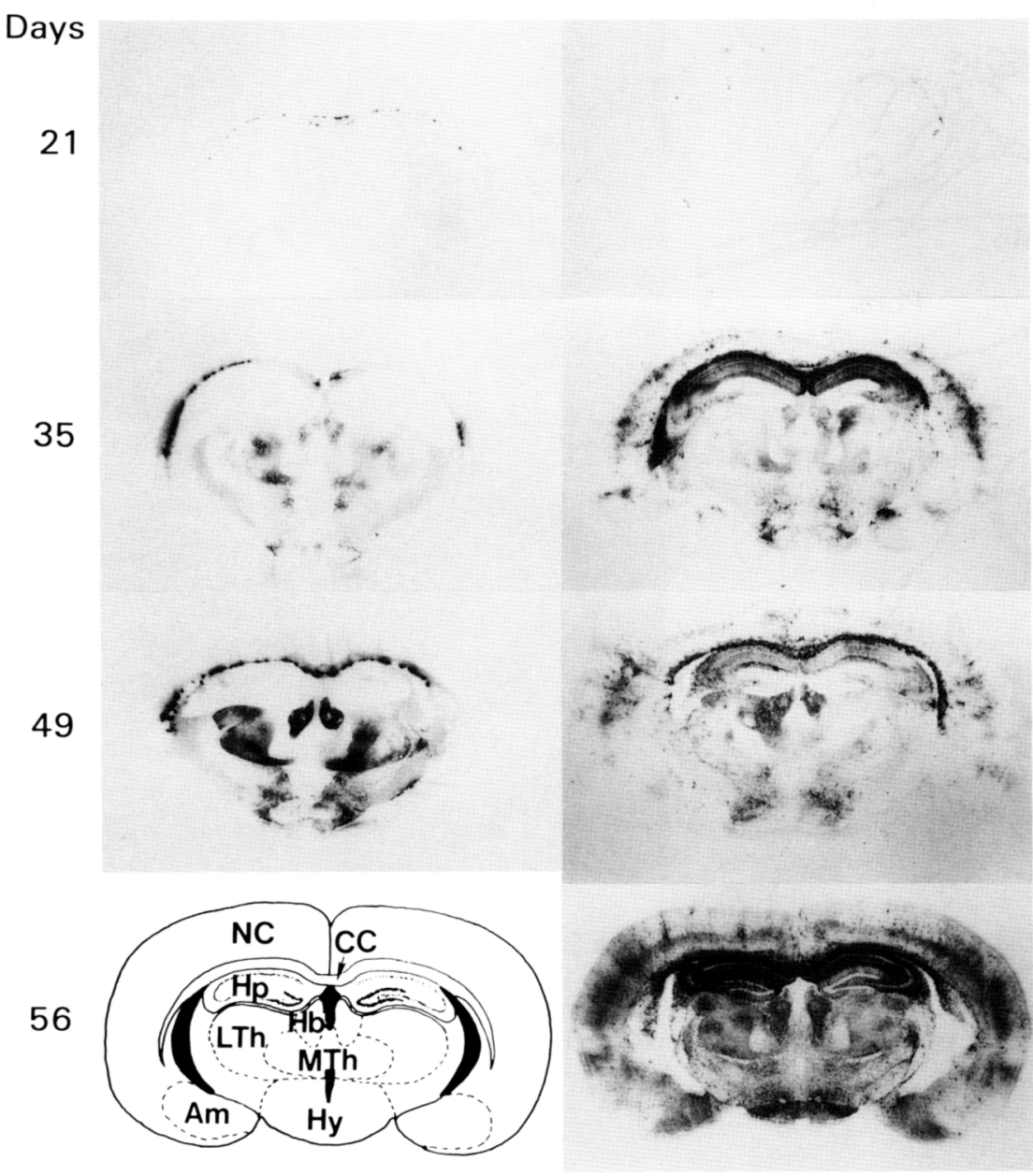

Figure 6. Kinetics of $\operatorname{Pr} \mathrm{P}^{\mathrm{Sc}}$ accumulation in the brains of transgenic mice expressing $\mathrm{SHaPrP}$ genes after inoculation with either Sc237 or $139 \mathrm{H}$ scrapie prions. Histoblots of coronal sections through the hippocampus and thalamus taken from $\mathrm{Tg}(\mathrm{SHaPrP}) 7$ mouse brains at $21,35,49$, and 56 days after inoculation with $\mathrm{Sc} 237$ or $139 \mathrm{H}$ prions. The prion inoculum contained $\sim 10^{7}$ $\mathrm{ID}_{50}$ units, and $30 \mu \mathrm{l}$ was inoculated intracerebrally. Histoblots were developed with the PrP antiserum R073. The diagram (lower left) identifies anatomical structures seen in coronal sections: (Am) Amygdala; (CC) corpus callosum; (Hb) habenula; (Hp) hippocampus; (Hy) hypothalamus; (LTh) lateral-ventral tier of thalamic nucleic; (MTh) medial thalamic group of nuclei; (NC) neocortex. site of inoculation in the thalamus as it did in Syrian hamsters inoculated with Sc237 prions. Rather, it first appeared in the form of extracellular plaque-like accumulations beneath the corpus callosum at 14-21 days. This finding suggests that the rate of release of newly formed $\mathrm{PrP}^{\mathrm{Sc}}$ from murine neurons in the thalamus, assuming synthesis there, was greater than the rate of retention. Second, a small number of brain regions in $\mathrm{Tg}$ [SHaPrP)7 mice accumulated $\mathrm{PrP}^{\mathrm{Sc}}$ with both Sc237 and $139 \mathrm{H}$, specifically the locus coeruleus, brain-stem raphe nuclei, habenula, hypothalamus, and lateral-ventral thalamus (Figs. 7 and 8).

\section{Discussion}

Although a converging body of evidence argues that infectious prions are devoid of foreign nucleic acids (Meyer et al. 1991; Prusiner 1991), the mechanism responsible for prion diversity remains enigmatic. The studies reported here offer a novel mechanism that might account for the diversity of prions in the absence of a scrapiespecific polynucleotide.

Although most studies of prion diversity have been performed with inbred mice, we chose to study two distinct isolates from Syrian hamsters with scrapie for the following reasons: (1) Incubation times of Sc237 and $139 \mathrm{H}$ prions are the shortest for any pair of distinct isolates (Kimberlin et al. 1987a); (2) the molecular properties of Sc237 prions and $\operatorname{PrP}^{\mathrm{Sc}}$ are the most extensively characterized (Gabizon and Prusiner 1990); (3) other hamster species have closely related but distinct $\operatorname{Pr} P$ genes (Lowenstein et al. 1990); and (4) transgenic mice expressing SHaPrP are well characterized with respect to Sc237 prions (Scott et al. 1989; Prusiner et al. 1990).

\section{Molecular properties of scrapie isolates}

$\mathrm{PrP}^{\mathrm{Sc}}$ is the only component of the infectious prion particle identified to date. Copurification of Sc237 prion infectivity and $\operatorname{PrP}^{\mathrm{Sc}}$ (or $\operatorname{PrP} 27-30$ ) is well established (Prusiner et al. 1982a, 1983; Gabizon et al. 1988). Purification protocols similar to those used for Sc237 prions were employed for $139 \mathrm{H}$ prions, resulting in fractions highly enriched for PrPsc. Our finding that PrP 27-30 molecules of Sc237 and $139 \mathrm{H}$ prions were indistinguishable by silver staining and immunoblotting after SDS- 


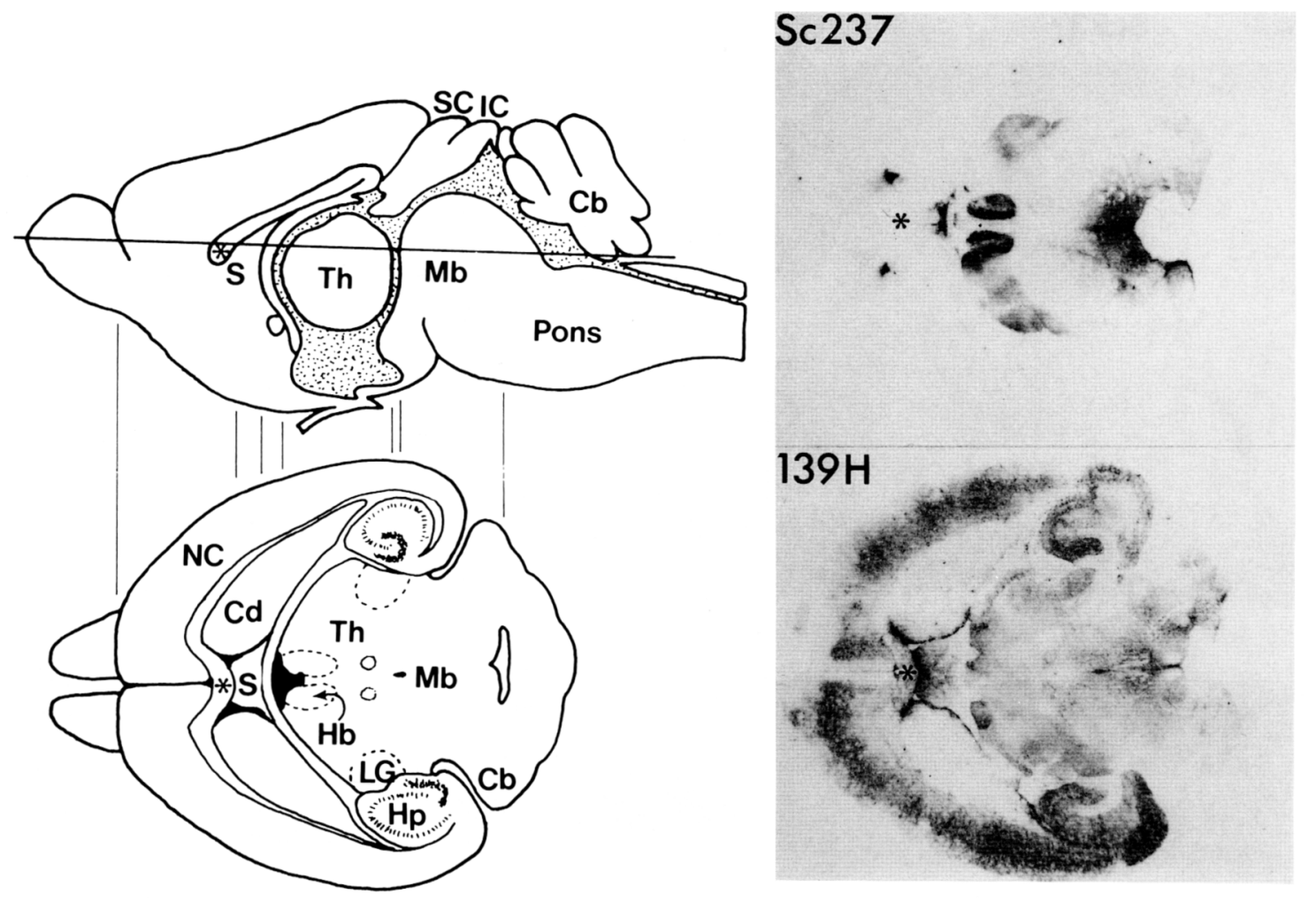

Figure 7. Distribution of $\mathrm{PrP}^{\mathrm{Sc}}$ in $\mathrm{Tg}(\mathrm{SHaPrP} \mid 7$ mice 49 days after inoculation with $\mathrm{Sc} 237$ or $139 \mathrm{H}$ prions in histoblots of horizontal sections of the brain through the thalamus. (Cb) Cerebellum; (Cd) caudate nucleus; $(\mathrm{Hb})$ habenula; ( $\mathrm{Hp}$ ) hippocampus; (IC) inferior colliculus; (Lg) lateral geniculate nucleus; $(\mathrm{Mb})$ midbrain; (NC) neocortex; (S) septum; (SC) superior colliculus; (Th) thalamus. The asterisk $(*)$ marks the region of the corpus callosum in the horizontal sections. The level of the plane of section is indicated in the sagittal brain diagram.

PAGE is in accord with earlier studies showing similar Western blotting patterns for various mouse and hamster isolates of scrapie prions (Kascsak et al. 1985, 1986). Digestion of $\operatorname{PrP} 27-30$ by endoproteinase Lys C followed by reverse-phase high-performance liquid chromatography (HPLC) failed to show any differences between the PrP peptides prepared from Syrian hamster brains inoculated with either Sc 237 or $139 \mathrm{H}$ prions, as assessed by liquid secondary ion and electrospray mass spectrometry (R. Hecker, M.A. Baldwin, N. Stahl, S. Hall, A.L. Burlingame, and S.B. Prusiner, in prep.). Similarly, studies on the structure of the glycoinositol phospholipid (GPI) anchor of $\mathrm{PrP}^{\mathrm{Sc}}$ failed to reveal any differences between the covalent structures of the GPI glycans from the two isolates (Stahl et al. 1992).

Electron microscopy was used to evaluate the ultrastructure of prion rods in purified fractions isolated from brains of Syrian hamsters inoculated with either Sc237 or $139 \mathrm{H}$ prions. Although prion rods were formed from both isolates under similar conditions (McKinley et al. 1991), the $139 \mathrm{H}$ rods appeared to be thicker and longer than those commonly found in Sc237 preparations (M. McKinley and R. Hecker, unpubl.). The parallel subfilaments of the $139 \mathrm{H}$ rods are reminiscent of rods found in purified fractions from human brains of patients dying of Creutzfeldt-Jakob disease (CJD) (Bockman et al. 1985).
These straight subfilaments contrast sharply with the helically wound subfilaments of scrapie-associated fibrils found in extracts of scrapie and CJD brains (Merz et al. 1981, 1983). Additional studies are needed to determine the structural basis of the apparent differences in the morphology of the prion rods in the Sc237 and $139 \mathrm{H}$ prion preparations.

\section{Replication of distinct isolates of Syrian hamster prions}

The first distinct isolates of scrapie prions exhibiting distinguishable phenotypes were found in goats based on their clinical signs and were designated either "drowsy" or "scratching" (Gordon and Pattison 1957; Pattison and Millson 1961; Pattison 1966). Later, prion isolates, or strains, were studied in mice on the basis of incubation time measurements and neuropathologic changes (Dickinson et al. 1968; Dickinson and Meikle 1971; Bruce and Dickinson 1987; Carp and Callahan 1991). Although the use of Prn- $p^{a}$ and Prn- $p^{b}$ strains of mice unknowingly complicated the study of distinct scrapie isolates (Westaway et al. 1987; Carlson et al. 1989), the existence of a limited number of isolates with distinct properties based on both incubation times and neuropathologic lesion profiles seems firmly established (Bruce et al. 1991). 

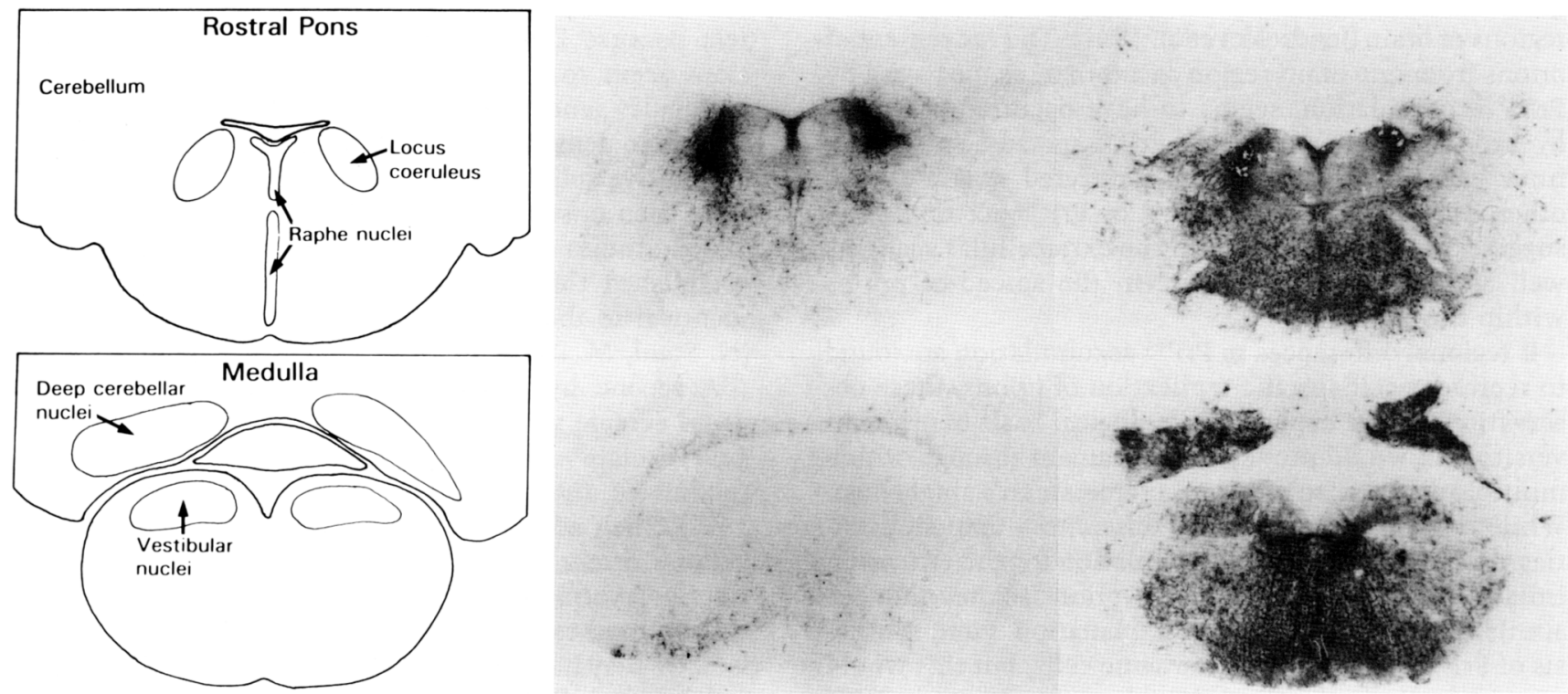

Figure 8. Histoblots of $\mathrm{PrP}^{\mathrm{Sc}}$ in transverse sections of the rostral pons and medulla 49 days after inoculation with $\mathrm{Sc} 237$ or $139 \mathrm{H}$ prions in $\mathrm{Tg}(\mathrm{SHaPrP}) 7$ mice. Structures that accumulate $\mathrm{PrP}^{\mathrm{Sc}}$ common to both prion isolates include the nucleus of locus coeruleus and raphe nuclei. Clinical signs of scrapie were the same with both inocula.

Our results with Sc237 prions inoculated into Syrian hamsters at increasing intervals after inoculation with $139 \mathrm{H}$ prions (Table 3) contrast with those reported by Dickinson and colleagues. They reported that inoculation of mice with a long incubation time isolate prevented replication of a short incubation time isolate that was inoculated later (Dickinson and Fraser 1972; Dickinson et al. 1975; Kimberlin and Walker 1985). For Sc237 and $139 \mathrm{H}$ prions, the lack of competition between these two isolates (Table 3 ) is consistent with the hypothesis that they are synthesized in different cells. Studies with $\mathrm{Tg}(\mathrm{SHaPrP})$ mice indicate that the replication of SHa prions is independent of Mo prions (Table 1), also raising the possibility of the two prions being replicated in the same or different populations of CNS cells. It will be important to determine whether murine prion isolates that are thought to compete with each other, replicate in the same cells or different ones.

\section{Fidelity of prion replication}

Investigations with transgenic mice contend that prions multiply through a mechanism where $\mathrm{PrP}^{\mathrm{C}} / \mathrm{PrP}^{\mathrm{Sc}}$ complexes feature as replication intermediates (Prusiner et al. 1990|. Although recent studies with hsp60 and p53 proteins (Cheng et al. 1990; Milner and Medcalf 1991) provide interesting precedents for the hypothesis that the conversion of $\operatorname{PrP}^{\mathrm{C}}$ to $\operatorname{PrP}^{\mathrm{Sc}}$ involves a conformational change, explaining multiple, stable scrapie isolates in terms of multiple, stable conformations of $\operatorname{Pr}^{\mathrm{Sc}}$ remains unprecedented. If the conformation of $\operatorname{PrP}^{\mathrm{Sc}} \mathrm{de}$ termines the properties of the Sc 237 and $139 \mathrm{H}$ prions, then passage into Chinese or Armenian hamsters must initiate the synthesis of different $\mathrm{CHaPrP}^{\mathrm{Sc}}$ or Armenian hamster $\operatorname{PrP}^{\mathrm{Sc}}\left(\mathrm{AHaPrP}^{\mathrm{Sc}}\right)$ molecules for each isolate (Table 4). In Chinese and Armenian hamsters with PrP gene sequences that differ from that of the Syrian hamster at 7 and 8 codons, respectively (Lowenstein et al. 1990), $139 \mathrm{H}$ produces incubation times that are either shorter or similar to those observed with Sc237 (Table 5). Upon repassage into Syrian hamsters, the Sc237 or $139 \mathrm{H}$ $\mathrm{CHaPrP}^{\mathrm{Sc}}$ and $\mathrm{AHaPrP}^{\mathrm{Sc}}$ molecules presumably direct the synthesis of Sc237 or $139 \mathrm{H} \mathrm{SHaPrP}{ }^{\mathrm{Sc}}$ molecules, respectively. These observations argue that heritable features can be perpetuated by transfer between $\mathrm{PrP}^{\mathrm{Sc}}$ molecules in spite of changes in PrP sequence among these three hamster species. Under these experimental conditions, the properties of the $\mathrm{Sc} 237$ and $139 \mathrm{H}$ isolates seem to be independent of the primary structure of PrP. However, passage of prions between species with larger differences in $\operatorname{PrP}$ primary structures such as those that distinguish MoPrP from $\mathrm{SHaPrP}$ seem to result in the frequent emergence of new isolates (Kimberlin et al. 1987b, 1989).

\section{Distinct prion isolates produce different patterns of $\operatorname{Pr} P^{S c}$ accumulation}

Although the concentration of $\mathrm{PrP}^{\mathrm{Sc}}$ and prion titers in brain homogenates was similar for the $\mathrm{Sc} 237$ and $139 \mathrm{H}$ isolates, the kinetics and patterns of $\operatorname{PrP}^{\mathrm{Sc}}$ accumulation for the two isolates were different (Figs. 4 and 5). The kinetics of $\operatorname{PrP}^{\mathrm{Sc}}$ accumulation in Syrian hamster brains inoculated with Sc237 prions, as determined by serial 
histoblots (Fig. 5A), were similar to those measured by quantitative Western blots of homogenates of dissected regions of brain (Jendroska et al. 1991). The movement of prions from one brain region to another, as measured by $\mathrm{PrP}^{\mathrm{Sc}}$ accumulation, seems to have occurred primarily by axonal transport because $\operatorname{PrP}^{\mathrm{Sc}}$ spread sequentially from one neuroanatomically connected region to another. However, some patterns of $\mathrm{PrP}^{\mathrm{Sc}}$ accumulation suggest that diffusion through the extracellular space, as well as the CSF, may feature in the spread of prions within the CNS.

If regional differences in $\mathrm{PrP}^{\mathrm{Sc}}$ accumulation are found to represent cell-specific replication of prions, these observations might explain the biological basis of prion diversity and would provide a mechanism through which multiple distinct isolates could replicate in a single host. While there were many more differences than similarities in the sites of $\operatorname{PrP}^{\mathrm{Sc}}$ accumulation for the two prion isolates, those regions in which prion isolates induced similar levels of $\operatorname{PrP}^{\mathrm{Sc}}$ require explanation. First, synthesis of $\mathrm{PrP} \mathrm{P}^{\mathrm{Sc}}$ could occur in the same cells, but this would seemingly limit the diversity of prions. Second, $\operatorname{Pr} \mathrm{P}^{\mathrm{Sc}}$ synthesis might proceed in different but adjacent cells in the same region. Third, the formation of $\mathrm{PrP}^{\mathrm{Sc}}$ might occur in different cells outside the region followed by transport to it.

That vacuolation correlates with the sites of $\mathrm{PrP}^{\mathrm{Sc}}$ accumulation (Fig. 4) is of interest with respect to many early studies on different prion isolates in mice. Murine scrapie isolates were characterized extensively by scoring the degree of neuropil vacuolation in different mouse brain regions (Fraser and Dickinson 1968, 1973). Those results, together with the correlative neuropathology and $\operatorname{Pr} \mathrm{P}^{\mathrm{Sc}}$ accumulation patterns (Fig. 4) reported here, raise the possibility that each prion isolate may have a distinct pattern of $\operatorname{PrP}^{\mathrm{Sc}}$ accumulation in brain.

Using immunohistochemical procedures (DeArmond et al. 1987), other investigators found that the intensity of regional PrP staining increased with scrapie and was specific for individual prion strains (Bruce et al. 1989). Although their conclusions are similar to ours in some respects, the immunostaining procedures that they used were not capable of distinguishing among several possibilities including increased $\mathrm{PrPC}^{\mathrm{C}}$ synthesis, diminished $\operatorname{PrP}^{\mathrm{C}}$ degradation, and $\operatorname{PrP}^{\mathrm{Sc}}$ accumulation. The histoblot technique permits assignment of the immunostaining signal to $\operatorname{PrP}^{\mathrm{Sc}}$ (Taraboulos et al. 1992).

\section{New approaches to prion diversity}

Many molecular models have been offered to explain the diversity and heritable properties of prions. Despite the lack of physical, chemical, and biological evidence for a scrapie-specific nucleic acid, the remote scenario that such a molecule exists remains a formal possibility to explain the distinct isolates of prions. The hypothesis that a given scrapie isolate can catalyze the synthesis of more of itself in the absence of a nucleic acid is rather unorthodox. In some respects, this hypothesis is reminiscent of early theories concerning the diversity and synthesis of antibodies (Burnet and Fenner 1949). Such theories now appear to be largely, if not entirely, incorrect because DNA rearrangements and somatic mutations seem to account for the diverse set of antibody molecules generated by mammals (Tonegawa 1983). Attempts to demonstrate DNA rearrangements, as well as alternative splicing and RNA editing of PrP transcripts, have been unsuccessful (Oesch et al. 1985; Basler et al. 1986). Studies of $\operatorname{PrP}^{\mathrm{Sc}}$ prepared from Sc237 prions have established that the amino acid sequence of $\operatorname{PrP}^{\mathrm{Sc}}$ is identical to that predicted from the PrP gene sequence (N. Stahl, M. Baldwin, and S.B. Prusiner, in prep.).

A second hypothesis suggests that $\operatorname{PrP}^{\mathrm{Sc}}$ alone can cause scrapie with the properties of Sc237 but that the $139 \mathrm{H}$ isolate contains an accessory RNA molecule that modulates the properties of this prion (Weissmann 1991). Such accessory RNAs are hypothesized to be of cellular origin and thus would not be detected by subtractive hybridization and differential cloning studies. A third hypothesis considers the possibility that scrapie isolates may have their origin in a non-PrP molecule that purifies with $\mathrm{PrP}^{\mathrm{Sc}}$ but is not a nucleic acid and, as yet, is undetected. A fourth possibility is that different chemical or conformational modifications of $\mathrm{PrP}^{\mathrm{Sc}}$ are responsible for the particular biological properties exhibited by scrapie prion isolates. Whether a particular isolate of infectious prions is composed of a uniform population of $\mathrm{PrP}^{\mathrm{Sc}}$ molecules or oligomers containing heterogeneously modified $\mathrm{PrP}^{\mathrm{Sc}}$ molecules remains to be determined.

The numerous sugar chain structures found in Asnlinked complex type oligosaccharides of $\mathrm{PrP}^{\mathrm{Sc}}$ (Endo et al. 1989; Prusiner 1989) make them candidates to regulate the apparent cell-specific targeting of prions. Asnlinked oligosaccharides seem likely to possess sufficient variation to account for the diversity of prion isolates that have been recorded. Many studies have shown that oligosaccharides as well as glycoproteins can bind to the surface of cells and act as ligands in cell-cell adhesion, modulators of neurite outgrowth, mediators of viral infection, and regulators of some hormonal activities (Wiley and Skehel 1987; Brandley et al. 1990; Doherty et al. 1991; Key and Akeson 1991; Takeuchi and Kobata 1991). However, studies with scrapie-infected cultured cells have shown that $\operatorname{PrP}^{\mathrm{Sc}}$ can be formed in the presence of tunicamycin and from recombinant PrP vectors with open reading frames (ORFs) mutated at the recognition sites for Asn-linked glycosylation (Taraboulos et al. 1990b). Whether unglycosylated $\mathrm{PrP}^{\mathrm{Sc}}$ can transmit disease and initiate production of more $\mathrm{PrP}^{\mathrm{Sc}}$ molecules is unknown. While the structures of the Asn-linked sugar chains of $\mathrm{PrP}^{\mathrm{Sc}}$ isolated from Syrian hamsters inoculated with Sc237 prions have been defined (Endo et al. 1989; Haraguchi et al. 1989), we have no knowledge of those linked to $\mathrm{PrP}^{\mathrm{Sc}}$ of $139 \mathrm{H}$ prions. Although lectinbinding studies have failed to reveal any differences in $\mathrm{PrP}^{\mathrm{Sc}}$ oligosaccharides among three Mo prion isolates (Somerville and Ritchie 1990), such studies can provide only limited information about the structure of the sugar chains. It is unlikely that the glycans of the GPI anchors 
attached to $\mathrm{PrP}^{\mathrm{Sc}}$ from $\mathrm{Sc} 237$ and $139 \mathrm{H}$ prions are isolate specific. Both GPI anchors have indistinguishable sugar chains, including sialic acid (Stahl et al. 1992), but many of the specific chemical bonds linking these sugars are unknown. A third possibility, as noted above, is that the diversity of prion strains might reside in the tertiary structure of $\mathrm{PrP}^{\mathrm{Sc}}$. Studies on two isolates of transmissible mink encephalopathy (TME) prions in hamsters support this hypothesis. One isolate with a 75-day incubation period shows $\operatorname{PrP}^{\mathrm{Sc}}$ protease resistance similar to that exhibited by $S c 237$, whereas the isolate with a 160day incubation period is considerably less protease resistant in contrast to $139 \mathrm{H}$ scrapie prions (Bessen and Marsh 1992).

Determining the limits of prion diversity and the mechanism by which "heritable" information is transferred during the replication of prions is of considerable interest. The results presented here offer a new view of prion replication in which prion diversity may be perpetuated by cell-specific replication. Studies with transgenic mice present convincing evidence that $\mathrm{PrP}^{\mathrm{Sc}} \mathrm{di}-$ rects the synthesis of nascent $\operatorname{PrP}^{\mathrm{Sc}}$ molecules (Prusiner et al. 1990), and the results of studies reported here support that hypothesis (Tables 1 and 2). If the replication of prions in specific cell types proves to be responsible for the properties of distinct isolates, then the cell-specific modification of $\mathrm{PrP}^{\mathrm{Sc}}$ must direct $\mathrm{PrP}^{\mathrm{Sc}}$ molecules to enter similar cells in the inoculated recipient for the isolate to "breed true." This hypothesis argues that cell-specific trophism generates a unique set of biological properties that are characteristic of an individual isolate.

\section{Materials and methods}

\section{Passage history and derivation hamster scrapie isolates}

After multiple passages in random-bred Syrian golden hamsters (Marsh and Kimberlin 1975), the scrapie agent was passaged in an Lak/LHC inbred Syrian hamster and the brain was given to us by Dr. Richard Marsh (Prusiner et al. 1980). Upon three subsequent passages in Lak/LVG hamsters, the pool of prions was enlarged and the fourth passage pool was designated Sc237 (Scott et al. 1989). Repeated passage of the scrapie agent in Lak/ LVG hamsters at limiting dilution produced the cloned isolate 263K (Kimberlin and Walker 1978). Many studies have been performed with Sc237 and 263K prions; they seem to exhibit similar properties in Syrian hamsters (Marsh and Hanson 1977; Prusiner et al. 1982b). After $>20$ passages of the Chandler isolate in mice, an isolate designated 139A was obtained (Dickinson 1976). Passage of mouse 139A prions in Lak/LVG Syrian golden hamsters produced the $139 \mathrm{H}$ isolate (Kimberlin et al. 1987b). After six passages in Syrian hamsters, $139 \mathrm{H}$ prions were provided to us by Drs. Richard Kimberlin and Richard Carp.

\section{Determination of scrapie incubation periods and prion bioassays}

Lak/LVG random-bred Syrian hamsters /Charles River Breeding Laboratories, Inc., Wilmington, MA) and inbred Armenian hamsters and Chinese hamsters (Cytogen, West Roxberry, MA) were inoculated with brain extracts as described previously (Prusiner et al. 1982a). Clinical diagnosis of scrapie in Syrian hamsters inoculated with $\sim 10^{7} \mathrm{ID}_{50}$ units of $\mathrm{Sc} 237$ prions has been de- scribed (Prusiner et al. 1982b). In Syrian hamsters inoculated with $\sim 10^{7} \mathrm{ID}_{50}$ units of $139 \mathrm{H}$, the first evidence of altered behavior appeared after 100-125 days. The hamsters exhibited agitation, increased aggressiveness, and frequent fighting with each other. Subsequently, neurologic dysfunction and weight gain became evident. By $\sim 160$ days, the hamsters exhibited signs of neurologic impairment manifest by truncal ataxia and bradykinesia. We used these signs to define the onset of illness for incubation time measurements. As clinical illness progressed, hamsters showed increasing difficulty righting themselves from a supine position. Syrian hamsters inoculated with $139 \mathrm{H}$ prions were obese compared with uninoculated controls. At the onset of illness, the inoculated hamsters weighed $233 \pm 3$ grams $(n=31)$, and age-matched uninoculated controls weighed $145 \pm 5$ grams $(n=16)$. Hamsters inoculated with Sc237 prions weighed $143 \pm 5$ grams $(n=8)$ at the onset of illness. $\mathrm{Tg}(\mathrm{SHaPrP})$ mice were constructed and produced at the University of California, San Francisco. Inoculation of these animals and determination of incubation times have been described (Scott et al. 1989; Prusiner et al. 1990).

End-point titrations of the scrapie agent were performed by intracerebral inoculation of six weanling female hamsters at 10 -fold dilutions ranging from $10^{-1}$ to $10^{-12}$, as described (Prusiner et al. 1982a). Hamsters inoculated with dilutions at $10^{-1}$ to $10^{-5}$ of $139 \mathrm{H}$ prions were housed three per cage. Because hamsters seem to grow more aggressive as they get older and fighting is more frequent resulting in non-scrapie-related deaths (Prusiner 1987), we housed hamsters receiving dilutions at $10^{-6}$ to $10^{-12}$ individually. Prion titers $\left(\mathrm{ID}_{50} / \mathrm{ml}\right)$ were calculated by use of the method of Spearman and Kärber (Dougherty 1964).

\section{Scrapie prion purification and measurement of $\operatorname{Pr} P$}

Large-scale purification of Sc237 prions was performed with a protocol employing discontinuous sucrose gradient centrifugation in a zonal rotor (Prusiner et al. 1983). Purification of $139 \mathrm{H}$ prions was performed on a smaller scale, typically with 100-200 brains from Syrian hamsters sacrificed $\sim 150$ days after intracerebral inoculation with $\sim 10^{7} \mathrm{ID}_{50}$ units by use of a protocol described previously (Prusiner et al. 1982a). Fraction P4 was either subjected to sucrose gradient centrifugation (Prusiner et al. 1982a) or to ultrafiltration. For ultrafiltration, the fraction P4 was adjusted to a protein concentration of $5-10 \mathrm{mg} / \mathrm{ml}$ in 20 mM Tris-OAc $(\mathrm{pH} 8.3), 1 \mathrm{~mm}$ EDTA, $1 \mathrm{mM}$ DTT, and $0.2 \%$ Sarkosyl. Before starting the ultrafiltration, fraction $\mathrm{P} 4$ was adjusted to $2 \%$ Triton X-100 and $0.8 \%$ SDS and incubated at room temperature for $15 \mathrm{~min}$. The buffer for the ultrafiltration was 20 mM Tris-OAc ( $\mathrm{pH} 8.3$ ) containing $2 \%$ Sarkosyl. The ultrafiltration was carried out in a $10-\mathrm{ml}$ Omega cell (Filtron, North Boro, MA) with an Omega membrane (exclusion limit, $300 \mathrm{kD}$ ). After $16 \mathrm{hr}, \sim 150 \mathrm{ml}$ of flowthrough accumulated. The retentate containing the prion rods was precipitated with 10 volumes of cold ethanol $\left(-20^{\circ} \mathrm{C}\right)$, or used directly.

The quantitation of PrP from brain homogenates was determined by a modified enzyme-linked immunosorbent assay (ELISA) as described in Prusiner et al. (1990), except that the $10 \%$ brain homogenate was prepared in $0.32 \mathrm{~m}$ sucrose. All samples were measured in triplicate.

\section{Neuropathologic studies and histoblots}

Brain tissue was immersion or perfusion fixed in $10 \%$ buffered formalin or periodate $/$ lysine $/ 0.5 \%$ paraformaldehyde fixative (DeArmond et al. 1987). In all cases, the brain tissue was embedded in paraffin, and 8 - $\mu \mathrm{m}$-thick histological sections were 
prepared. The sections were then treated with proteinase $\mathrm{K}(5$ $\mu \mathrm{g} / \mathrm{ml}$ ) for $10 \mathrm{~min}$ at room temperature followed by three rinses with PBS. Each section was treated with $3 \mathrm{M}$ guanidinium thiocyanate for $10 \mathrm{~min}$ because this denaturation step was found to greatly enhance immunoreactivity of proteinase K-resistant $\operatorname{PrP}$ on Western transblots (Serban et al. 1990; Taraboulos et al. 1990a).

Cryostat sections (8 $\mu \mathrm{m}$ thick) on glass slides were blotted onto nitrocellulose membranes, as described previously (Taraboulos et al. 1992). To determine the precise neuroanatomical localization of $\mathrm{PrP}^{\mathrm{Sc}}$ accumulation in histoblots, adjacent serial sections were mounted on glass slides and stained with hematoxylin and eosin.

\section{Acknowledgments}

This work was supported by research grants from the National Institutes of Health and the American Health Assistance Foundation, as well as by gifts from Sherman Fairchild Foundation and National Medical Enterprises. R.H. was supported by a European Molecular Biology Organization fellowship. We thank Drs. Rudi Meyer, George Carlson, and Charles Weissmann for stimulating discussions. The technical support of Dallas Foster, Darlene Groth, and Hana Serban is gratefully acknowledged.

The publication costs of this article were defrayed in part by payment of page charges. This article must therefore be hereby marked "advertisement" in accordance with 18 USC section 1734 solely to indicate this fact.

\section{References}

Barry, R.A. and S.B. Prusiner. 1986. Monoclonal antibodies to the cellular and scrapie prion proteins. I. Infect. Dis. 154: $518-521$.

Basler, K., B. Oesch, M. Scott, D. Westaway, M. Wälchli, D.F. Groth, M.P. McKinley, S.B. Prusiner, and C. Weissmann. 1986. Scrapie and cellular PrP isoforms are encoded by the same chromosomal gene. Cell 46: 417-428.

Bessen, R.A. and R.F. Marsh. 1992. Biochemical and physical properties of the prion protein from two strains of the transmissible mink encephalopathy agent. I. Virol. 66: 20962101.

Bockman, J.M., D.T. Kingsbury, M.P. McKinley, P.E. Bendheim, and S.B. Prusiner. 1985. Creutzfeldt-Jakob disease prion proteins in human brains. N. Engl. J. Med. 312: 73-78.

Brandley, B.K., S.J. Swiedler, and P.W. Robbins. 1990. Carbohydrate ligands of the LEC cell adhesion molecules. Cell 63: $861-863$.

Bruce, M.E. and A.G. Dickinson. 1987. Biological evidence that the scrapie agent has an independent genome. J. Gen. Virol. 68: 79-89.

Bruce, M.E., P.A. McBride, and C.F. Farquhar. 1989. Precise targeting of the pathology of the sialoglycoprotein, $\operatorname{PrP}$, and vacuolar degeneration in mouse scrapie. Neurosci. Lett. 102: $1-6$.

Bruce, M.E., I. McConnell, H. Fraser, and A.G. Dickinson. 1991. The disease characteristics of different strains of scrapie in Sinc congenic mouse lines: Implications for the nature of the agent and host control of pathogenesis. J. Gen. Virol. 72: 595-603.

Burnet, F.M. and F. Fenner. 1949. The production of antibodies-Monograph of the Walter and Eliza Hall Institute, Melbourne. Macmillan and Company, London, England.

Carlson, G.A., D.T. Kingsbury, P.A. Goodman, S. Coleman, S.T. Marshall, S.J. DeArmond, D. Westaway, and S.B. Prusiner.
1986. Linkage of prion protein and scrapie incubation time genes. Cell 46: 503-511.

Carlson, G.A., P.A. Goodman, M. Lovett, B.A. Taylor, S.T. Marshall, M. Peterson-Torchia, D. Westaway, and S.B. Prusiner. 1988. Genetics and polymorphism of the mouse prion gene complex: The control of scrapie incubation time. Mol. Cell. Biol. 8: 5528-5540.

Carlson, G.A., D. Westaway, S.J. DeArmond, M. Peterson-Torchia, and S.B. Prusiner. 1989. Primary structure of prion protein may modify scrapie isolate properties. Proc. Natl. Acad. Sci. 86: 7475-7479.

Carp, R.I. and S.M. Callahan. 1991. Variation in the characteristics of 10 mouse-passaged scrapie lines derived from five scrapie-positive sheep. J. Gen. Virol. 72: 293-298.

Cheng, M.Y., F.U. Hartl, and A.L. Horwich. 1990. The mitochondrial chaperonin hsp 60 is required for its own assembly. Nature 348: 455-458.

DeArmond, S.J., M.P. McKinley, R.A. Barry, M.B. Braunfeld, J.R. McColloch, and S.B. Prusiner. 1985. Identification of prion amyloid filaments in scrapie-infected brain. Cell 41: 221235.

DeArmond, S.J., W.C. Mobley, D.L. DeMott, R.A. Barry, J.H. Beckstead, and S.B. Prusiner. 1987. Changes in the localization of brain prion proteins during scrapie infection. Neurology 37: 1271-1280.

Dickinson, A.G. 1976. Scrapie in sheep and goats. In Slow virus diseases of animals and man (ed. R.H. Kimberlin), pp. 209241. North-Holland Publishing, Amsterdam, The Netherlands.

Dickinson, A.G. and V.M.H. Meikle. 1971. Host-genotype and agent effects in scrapie incubation: Change in allelic interaction with different strains of agent. Mol. Gen. Genet. 112: 73-79.

Dickinson, A.G. and H. Fraser. 1972. Scrapie: Effect of Dh gene on the incubation period of extraneurally injected agent. $\mathrm{He}$ redity 29: 91-93.

Dickinson, A.G., V.M.H. Meikle, and H. Fraser. 1968. Identification of a gene which controls the incubation period of some strains of scrapie agent in mice. I. Comp. Pathol. 78: 293-299.

Dickinson, A.G., H. Fraser, V.M.H. Meikle, and G.W. Outram. 1972. Competition between different scrapie agents in mice. Nat. New Biol. 237: 244-245.

Dickinson, A.G., H. Fraser, and G.W. Outram. 1975. Scrapie incubation time can exceed natural lifespan. Nature 256: 732-733.

Doherty, P., L.H. Rowett, S.E. Moore, D.A. Mann, and F.S. Walsh. 1991. Neurite outgrowth in response to transfected $\mathrm{N}$-CAM and $\mathrm{N}$-cadherin reveals fundamental differences in neuronal responsiveness to CAMs. Neuron 6: 247-258.

Dougherty, R. 1964. Animal virus titration techniques. In Techniques in experimental virology (ed. R.J.C. Harris), pp. 169224. Academic Press, New York.

Endo, T., D. Groth, S.B. Prusiner, and A. Kobata. 1989. Diversity of oligosaccharide structures linked to asparagines of the scrapie prion protein. Biochemistry 28: 8380-8388.

Fraser, H. and A.G. Dickinson. 1968. The sequential development of the brain lesions of scrapie in three strains of mice. I. Comp. Pathol. 78: 301-311.

- 1973. Scrapie in mice. Agent-strain differences in the distribution and intensity of grey matter vacuolation. $I$. Comp. Pathol. 83: 29-40.

Gabizon, R. and S.B. Prusiner. 1990. Prion liposomes. Biochem. J. 266: 1-14.

Gabizon, R., M.P. McKinley, D.F. Groth, and S.B. Prusiner. 1988. Immunoaffinity purification and neutralization of 
scrapie prion infectivity. Proc. Natl. Acad. Sci. 85: 66176621.

Gordon, W.S. and I.H. Pattison. 1957. The experimental production of scrapie in goats. Vet. Rec. 69: 1444.

Haraguchi, T., S. Fisher, S. Olofsson, T. Endo, D. Groth, A. Tarantino, D.R. Borchelt, D. Teplow, L. Hood, A. Burlingame, E. Lycke, A. Kobata, and S.B. Prusiner. 1989. Asparagine-linked glycosylation of the scrapie and cellular prion proteins. Arch. Biochem. Biophys. 274: 1-13.

Hsiao, K.K., M. Scott, D. Foster, D.F. Groth, S.J. DeArmond, and S.B. Prusiner. 1990. Spontaneous neurodegeneration in transgenic mice with mutant prion protein of GerstmannSträussler syndrome. Science 250: 1587-1590.

Hunter, N., J. Hope, I. McConnell, and A.G. Dickinson. 1987. Linkage of the scrapie-associated fibril protein $(\operatorname{PrP})$ gene and Sinc using congenic mice and restriction fragment length polymorphism analysis. J. Gen. Virol. 68: 2711-2716.

Jendroska, K., F.P. Heinzel, M. Torchia, L. Stowring, H.A. Kretzschmar, A. Kon, A. Stern, S.B. Prusiner, and S.J. DeArmond. 1991. Proteinase-resistant prion protein accumulation in Syrian hamster brain correlates with regional pathology and scrapie infectivity. Neurology 41: 1482-1490.

Kascsak, R.J., R. Rubenstein, P.A. Merz, R.I. Carp, H.M. Wisniewski, and H. Diringer. 1985. Biochemical differences among scrapie-associated fibrils support the biological diversity of scrapie agents. I. Gen. Virol. 66: 1715-1722.

Kascsak, R.J., R. Rubenstein, P.A. Merz, R.I. Carp, N.K. Robakis, H.M. Wisniewski, and H. Diringer. 1986. Immunological comparison of scrapie-associated fibrils isolated from animals infected with four different scrapie strains. J. Virol. 59: 676-683.

Key, B. and R.A. Akeson. 1991. Delineation of olfactory pathways in the frog nervous system by unique glycoconjugates and N-CAM glycoforms. Neuron 6: 381-396.

Kimberlin, R. and C. Walker. 1977. Characteristics of a short incubation model of scrapie in the golden hamster. I. Gen. Virol. 34: 295-304.

1978. Evidence that the transmission of one source of scrapie agent to hamsters involves separation of agent strains from a mixture. J. Gen. Virol. 39: 487-496.

1985. Competition between strains of scrapie depends on the blocking agent being infectious. Intervirology 23: 74 81.

Kimberlin, R.H., S. Cole, and C.A. Walker. 1987a. Pathogenesis of scrapie is faster when infection is intraspinal instead of intracerebral. Microb. Pathog. 2: 405-415.

- 1987b. Temporary and permanent modifications to a single strain of mouse scrapie on transmission to rats and hamsters. J. Gen. Virol. 68: 1875-1881.

Kimberlin, R.H., C.A. Walker, and H. Fraser. 1989. The genomic identity of different strains of mouse scrapie is expressed in hamsters and preserved on reisolation in mice. I. Gen. Virol. 70: 2017-2025.

Laemmli, U.K. 1970. Cleavage of structural proteins during the assembly of the head of bacteriophage T-4. Nature 227: 680685.

Lowenstein, D.H., D.A. Butler, D. Westaway, M.P. McKinley, S.J. DeArmond, and S.B. Prusiner. 1990. Three hamster species with different scrapie incubation times and neuropathological features encode distinct prion proteins. Mol. Cell. Biol. 10: 1153-1163.

Marsh, R.F. and R.P. Hanson. 1977. The Syrian hamster as a model for the study of slow virus diseases caused by unconventional agents. Fed. Proc. 37: 2076-2078.

Marsh, R.F. and R.H. Kimberlin. 1975. Comparison of scrapie and transmissible mink encephalopathy in hamsters. II.
Clinical signs, pathology and pathogenesis. I. Infect. Dis. 131: 104-110.

McKinley, M.P., D.C. Bolton, and S.B. Prusiner. 1983. A protease-resistant protein is a structural component of the scrapie prion. Cell 35: 57-62.

McKinley, M.P., R. Meyer, L. Kenaga, F. Rahbar, R. Cotter, A. Serban, and S.B. Prusiner. 1991. Scrapie prion rod formation in vitro requires both detergent extraction and limited proteolysis. J. Virol. 65: 1440-1449.

Merz, P.A., R.A. Somerville, H.M. Wisniewski, and K. Iqbal. 1981. Abnormal fibrils from scrapie-infected brain. Acta Neuropathol. 54: 63-74.

Merz, P.A., R.A. Somerville, H.M. Wisniewski, L. Manuelidis, and E.E. Manuelidis. 1983. Scrapie-associated fibrils in Creutzfeldt-Jakob disease. Nature 306: 474-476.

Meyer, N., V. Rosenbaum, B. Schmidt, K. Gilles, C. Mirenda, D. Groth, S.B. Prusiner, and D. Riesner. 1991. Search for a putative scrapie genome in purified prion fractions reveals a paucity of nucleic acids. I. Gen. Virol. 72: 37-49.

Milner, J. and E.A. Medcalf. 1991. Cotranslation of activated mutant $\mathrm{p} 53$ with wild type drives the wild-type $\mathrm{p} 53$ protein into the mutant conformation. Cell 65: 765-774.

Oesch, B., D. Westaway, M. Wälchli, M.P. McKinley, S.B.H. Kent, R. Aebersold, R.A. Barry, P. Tempst, D.B. Teplow, L.E. Hood, S.B. Prusiner, and C. Weissmann. 1985. A cellular gene encodes scrapie PrP 27-30 protein. Cell 40: 735-746.

Pattison, I.H. 1966. The relative susceptibility of sheep, goats and mice to two types of the goat scrapie agent. Res. Vet. Sci. 7: 207-212.

Pattison, I.H. and G.C. Millson. 1961. Scrapie produced experimentally in goats with special reference to the clinical syndrome. I. Comp. Pathol. 71: 101-108.

Prusiner, S.B. 1987. The biology of prion transmission and replication. In Prions-Novel infectious pathogens causing scrapie and Creutzfeldt-lakob disease (ed. S.B. Prusiner and M.P. McKinley), pp. 83-112. Academic Press, Orlando, FL. 374.

- 1991. Molecular biology of prion diseases. Science 252: 1515-1522.

Prusiner, S.B., D.F. Groth, S.P. Cochran, F.R. Masiarz, M.P. McKinley, and H.M. Martinez. 1980. Molecular properties, partial purification, and assay by incubation period measurements of the hamster scrapie agent. Biochemistry 19: 48834891.

Prusiner, S.B., D.C. Bolton, D.F. Groth, K.A. Bowman, S.P. Cochran, and M.P. McKinley. 1982a. Further purification and characterization of scrapie prions. Biochemistry 21: 69426950.

Prusiner, S.B., S.P. Cochran, D.F. Groth, D.E. Downey, K.A. Bowman, and H.M. Martinez. 1982b. Measurement of the scrapie agent using an incubation time interval assay. Ann. Neurol. 11: 353-358.

Prusiner, S.B., M.P. McKinley, K.A. Bowman, D.C. Bolton, P.E. Bendheim, D.F. Groth, and G.G. Glenner. 1983. Scrapie prions aggregate to form amyloid-like birefringent rods. Cell 35: 349-358.

Prusiner, S.B., M. Scott, D. Foster, K.-M. Pan, D. Groth, C. Mirenda, M. Torchia, S.-L. Yang, D. Serban, G.A. Carlson, P.C. Hoppe, D. Westaway, and S.J. DeArmond. 1990. Transgenetic studies implicate interactions between homologous PrP isoforms in scrapie prion replication. Cell 63: 673-686.

Race, R.E., K. Graham, D. Ernst, B. Caughey, and B. Chesebro. 1990. Analysis of linkage between scrapie incubation period and the prion protein gene in mice. J. Gen. Virol. 71: 493497. 
Scott, M., D. Foster, C. Mirenda, D. Serban, F. Coufal, M. Wälchli, M. Torchia, D. Groth, G. Carlson, S.J. DeArmond, D. Westaway, and S.B. Prusiner. 1989. Transgenic mice expressing hamster prion protein produce species-specific scrapie infectivity and amyloid plaques. Cell 59: 847-857.

Serban, D., A. Taraboulos, S.J. DeArmond, and S.B. Prusiner. 1990. Rapid detection of Creutzfeldt-Jakob disease and scrapie prion proteins. Neurology 40: 110-117.

Somerville, R.A. and L.A. Ritchie. 1990. Differential glycosylation of the protein $(\mathrm{PrP})$ forming scrapie-associated fibrils. $J$. Gen. Virol. 71: 833-839.

Stahl, N., M.A. Baldwin, R. Hecker, K.-M. Pan, A.L. Burlingame, and S.B. Prusiner. 1992. Glycosylinositol phospholipid anchors of the scrapie and cellular prion proteins contain sialic acid. Biochemistry (in press).

Takeuchi, M. and A. Kobata. 1991. Structures and functional roles of the sugar chains of human erythropoietins. Glycobiology 1: 337-346.

Taraboulos, A., M. Rogers, D.R. Borchelt, M.P. McKinley, M. Scott, D. Serban, and S.B. Prusiner. 1990a. Acquisition of protease resistance by prion proteins in scrapie-infected cells does not require asparagine-linked glycosylation. Proc. Natl. Acad. Sci. 87: 8262-8266.

Taraboulos, A., D. Serban, and S.B. Prusiner. 1990b. Scrapie prion proteins accumulate in the cytoplasm of persistentlyinfected cultured cells. J. Cell Biol. 110: 2117-2132.

Taraboulos, A., K. Jendroska, D. Serban, S.-L. Yang, S.J. DeArmond, and S.B. Prusiner. 1992. Regional mapping of prion proteins in brains. Proc. Natl. Acad. Sci. (in press).

Tonegawa, S. 1983. Somatic generation of antibody diversity. Nature 302: 575-581.

Turk, E., D.B. Teplow, L.E. Hood, and S.B. Prusiner. 1988. Purification and properties of the cellular and scrapie hamster prion proteins. Eur. I. Biochem. 176: 21-30.

Weissmann, C. 1991. A "unified theory" of prion propagation. Nature 352: 679-683.

Westaway, D., P.A. Goodman, C.A. Mirenda, M.P. McKinley, G.A. Carlson, and S.B. Prusiner. 1987. Distinct prion proteins in short and long scrapie incubation period mice. Cell 51: 651-662.

Westaway, D., C.A. Mirenda, D. Foster, Y. Zebarjadian, M. Scott, M. Torchia, S.-L. Yang, H. Serban, S.J. DeArmond, C. Ebeling, S.B. Prusiner, and G.A. Carlson. 1991. Paradoxical shortening of scrapie incubation times by expression of prion protein transgenes derived from long incubation period mice. Neuron 7: 59-68.

Wiley, D.C. and J.J. Skehel. 1987. The structure and function of the hemagglutinin membrane glycoprotein of influenza virus. Annu. Rev. Biochem. 56: 365-394. 


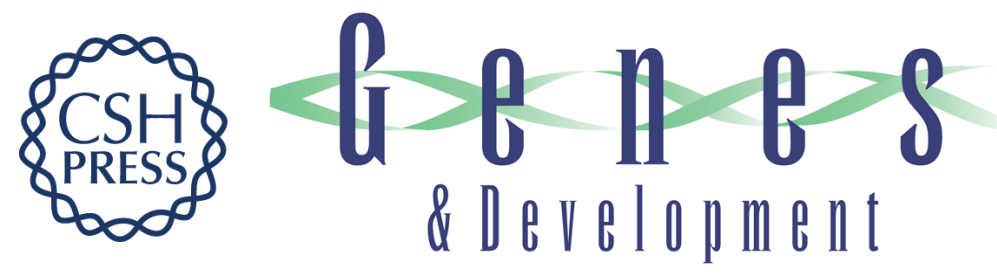

\section{Replication of distinct scrapie prion isolates is region specific in brains of transgenic mice and hamsters.}

R Hecker, A Taraboulos, M Scott, et al.

Genes Dev. 1992, 6:

Access the most recent version at doi:10.1101/gad.6.7.1213

References This article cites 73 articles, 15 of which can be accessed free at: http://genesdev.cshlp.org/content/6/7/1213.full.html\#ref-list-1

License

Email Alerting

Service

Receive free email alerts when new articles cite this article - sign up in the box at the top right corner of the article or click here.

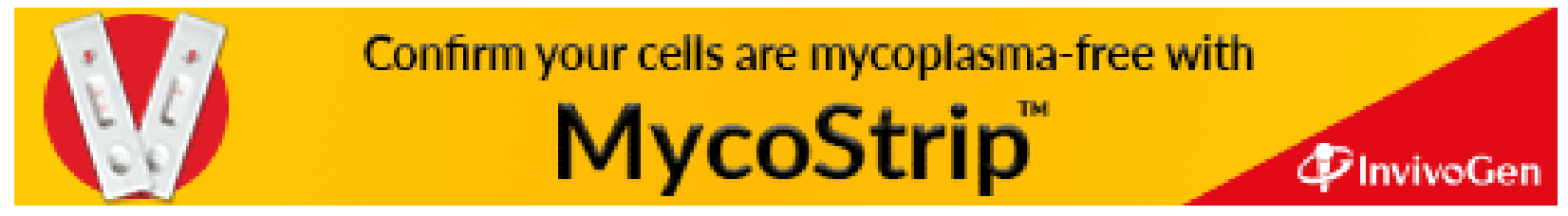

